\title{
Role of Nanostructure in Electrochemical Corrosion and High Temperature Oxidation: A Review
}

\begin{abstract}
B.V. MAHESH and R.K. SINGH RAMAN
The extremely fine grain size of nanocrystalline (nc) metallic alloys results in significantly different mechanical, electrochemical and oxidation properties as compared to the coarse-grained alloys of the same composition. Although the synthesis and attractive mechanical properties of nanocrystalline materials have been investigated and reviewed in great depth, the high temperature oxidation and electrochemical corrosion of these materials has received limited attention. The difference in the active dissolution and passivation behavior of nc alloys as compared to their microcrystalline counterparts varies for each alloy system. However, a unified theory explaining these phenomena still eludes us. In this context, this article reviews the progress in the electrochemical corrosion behavior of different nanocrystalline alloys, and hence, develops a better understanding of the effect of grain size, composition, interfacial phenomena and selective dissolution on corrosion of nanocrystalline alloys. This review also presents the role of nanometric grain size and the associated increase in grain boundary diffusion on the high temperature oxidation of nc alloys. The attractive possibility of enhanced oxidation resistance at lower alloying additions as compared to the coarse-grained alloys has been discussed. Although the primary focus of the article is on ferrous alloy systems, however, the lead studies on the role of ultrafine grain size in oxidation/corrosion behavior of other alloys systems have also been reviewed.
\end{abstract}

DOI: $10.1007 / \mathrm{s} 11661-014-2452-5$

(C) The Minerals, Metals \& Materials Society and ASM International 2014

\section{INTRODUCTION}

NANOCRYSTALLINE solids are single or multiphase polycrystalline materials with grain size typically less than $100 \mathrm{~nm}^{[1,2]}$ They have been extensively studied because of their distinct properties which have been attributed to their extremely fine grain size and a remarkably high volume fraction of interfaces (intercrystalline component composed of grain boundaries and triple junctions). ${ }^{[3,4]}$ For example, the nanocrystalline alloys possess considerably high mechanical strength, faster diffusion of alloying elements, higher specific heat and electrical resistivity as compared to their coarse-grained counterparts. Recent research has revolved around the exploitation of attractive physical properties of nanocrystalline alloys for engineering applications. Several of such applications require the materials to demonstrate acceptable levels of resistance to corrosion. A proper understanding of degradation of nanocrystalline metals/alloys due to corrosion is particularly important since grain size and grain boundaries are known to influence corrosion processes. ${ }^{[5-7]}$ High

B.V. MAHESH, formerly Ph.D. Student with the Department of Mechanical and Aerospace Engineering, Monash University, Clayton, VIC, Australia, is now Post-doctoral Fellow with the Center for Clean Energy Engineering, University of Connecticut, Storrs, CT. R.K. SINGH RAMAN, Professor, is with the Department of Mechanical and Aerospace Engineering, Monash University, and also with the Department of Chemical Engineering, Monash University. Contact e-mail: Raman.Singh@monash.edu

Manuscript submitted January 26, 2014.

Article published online June 23, 2014 temperature oxidation and electrochemical corrosion resistance of nanocrystalline metals and alloys have received limited research attention. However, nanocrystalline metals and alloys have been reported to exhibit different oxidation/corrosion resistance to their microcrystalline counterparts. ${ }^{[8-11]}$ It is also emphasized that besides the interest in investigating the role of nanocrystalline structure in oxidation/corrosion, another attractive aspect is the possibility of exploiting the enhanced grain boundary diffusion for the purpose of developing oxidation/corrosion resistant alloys with considerably less alloying contents. ${ }^{[8]}$ In this context, developing commercially viable material processing routes for producing and retaining nanocrystalline structure of oxidation/corrosion resistant alloys is a major but non-trivial challenge. This review provides a brief description of the challenges in the synthesis of nanocrystalline metals and alloys, and their thermal stability, mechanical properties and oxidation/corrosion. Though ferrous alloy systems are the major focus of this review, the lead studies on the role of nanocrystalline grain size in oxidation/corrosion behavior of nonferrous systems have also been reviewed.

\section{STRUCTURE AND PROPERTIES OF NANOCRYSTALLINE ALLOYS}

Though there are variations of a few orders of magnitude in their grain size, the structure and dimensions of grain boundaries in nanocrystalline (nc) and microcrystalline materials have been suggested to be 
fundamentally similar. ${ }^{[12-17]}$ However, based on thermodynamic properties of nanocrystalline materials, Fecht ${ }^{[18]}$ suggested the grain boundary energy to be considerably greater in the case of nanocrystalline iron (produced by ball milling) as compared to the same metal in the microcrystalline state. Several other researchers believe grain boundaries in nanocrystalline state to be more disordered than in the conventional microcrystalline materials. ${ }^{[19-23]}$ Though the 'grains' and 'grain boundaries' in nanocrystalline state have been visualized in a way which is remarkably different from the traditional concept of large grains separated by considerably thin boundaries in the case of conventional microcrystalline materials, in this review, the terms 'grains' and 'grain boundaries' will continue to be used in the traditional sense. However, it is important to reflect that the structure of nc-materials is visualized as consisting of two components: a crystalline component (CC), which is formed by small equiaxed single crystals and the intercrystalline component (IC), ${ }^{[12,24]}$ as shown in Figure 1. The IC component forms a network and surrounds the $\mathrm{CC}$ crystallites. The fraction of $\mathrm{IC}$ increases with decreasing size of crystallites and may even exceed $\mathrm{CC}$ fraction (when the crystallites are of sizes below a critical size).

As described earlier, because of their remarkably fine grain size, the grain boundaries constitute a remarkably large volume fraction of nanocrystalline (nc) materials. As a result, those mechanical, electrical, magnetic, and chemical properties that profoundly depend on grain size and grain-boundary phenomena are also significantly different in the case of nc materials as compared to their microcrystalline (mc) counterparts. Though nanocrystalline structure and grain size can influence most properties, of particular relevance to this review are the thermal stability, mechanical and diffusion characteristics of nanocrystalline materials.

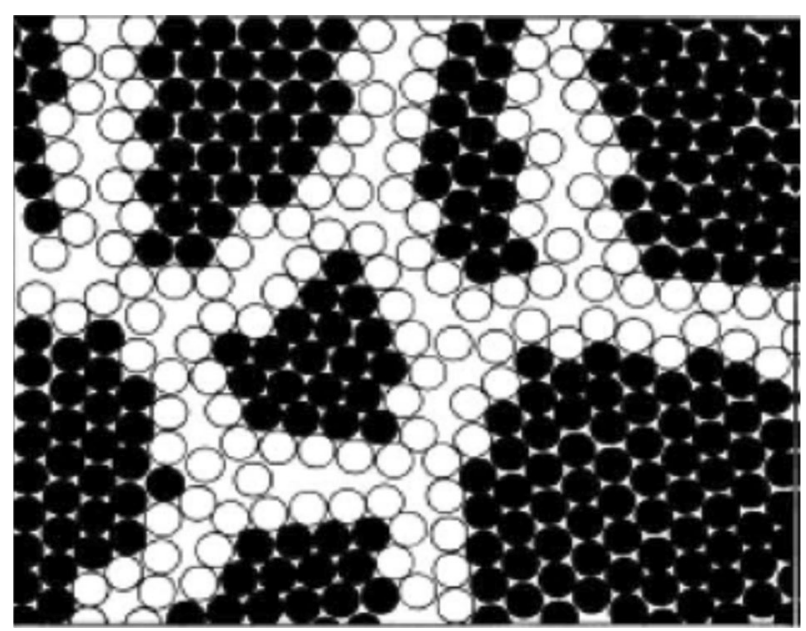

Fig. 1-Model of a nanostructured material: filled circles represent crystalline component atoms whereas the open circles represent intercrystalline component atoms. ${ }^{[12,24]}$

\section{THERMAL STABILITY AND SYNTHESIS OF NANOCRYSTALLINE ALLOYS}

\section{A. Thermal Stability}

The interfacial energy of the nanocrystalline materials is generally considerably high owing to the remarkably high volume fraction of the IC (shown in Figure 1). Consequently, the nc materials are exceedingly susceptible to grain growth at elevated temperatures ${ }^{[12,24]}$ that decreases the total energy of the system. An important feature in designing nanocrystalline alloys is to take into account the ability of the alloy to resist grain growth and retain the nanocrystallinity at elevated temperatures. Thermal instability may also be a factor before any elevated temperature engineering application of nanocrystalline materials (such as resistance to oxidation by high temperature gases). According to the well-known Gibbs-Thompson equation, the driving force for grain growth process in conventional polycrystals can be expressed as,

$$
\Delta \mu=\frac{2 \gamma V_{\mathrm{a}}}{d},
$$

where $V_{\mathrm{a}}$ is the atomic volume, $\gamma$ is the interfacial energy, and $d$ is the crystallite size. Due to the presence of high density of interfaces and nanometre-sized grains in nanocrystalline materials, it is expected that the grain growth will be quite rapid for nanocrystalline materials, sometimes, even at very low temperatures. For example, low melting engineering metals, namely, $\mathrm{Sn}, \mathrm{Pb}, \mathrm{Al}$, and $\mathrm{Mg}$ can undergo considerable grain growth even at room temperature. ${ }^{[24,25]}$ However, contrary to the expectations, experimental observations indicate that most nanocrystalline materials, synthesized by various methods, exhibit inherent grain size stabilities up to reasonably high temperatures $\left(0.4 \text { to } 0.5 T_{\mathrm{m}}\right)^{[24,26-29]}$ which is comparable with that of grain growth in conventional coarse-grained polycrystalline materials. ${ }^{[26-29]}$ For example, iron and iron based-alloys resist grain growth up to $673 \mathrm{~K}$ to $873 \mathrm{~K}\left(400{ }^{\circ} \mathrm{C}\right.$ to $\left.600{ }^{\circ} \mathrm{C}\right) .{ }^{[12,28,30-35]}$ Similar behavior has been reported for other metals $\left(\right.$ e.g., $\left.\mathrm{Co}^{[36]}\right)$. However, there are some inconsistencies in the literature on the temperature at which rapid grain growth is initiated. In their study on grain growth of pulsed electrodeposited nc-Fe, Natter et $a l^{[34]}$ reported a sudden grain growth at $683 \mathrm{~K}$ $\left(410^{\circ} \mathrm{C}\right)$, whereas Malow and $\mathrm{Koch}^{[28]}$ did not find such behavior until a temperature range of $773 \mathrm{~K}$ to $803 \mathrm{~K}$ $\left(500{ }^{\circ} \mathrm{C}\right.$ to $\left.530{ }^{\circ} \mathrm{C}\right)$. Such inconsistencies are generally attributed to the presence of different levels of impurities in the nc materials that may come inherently from processing route employed in different studies. ${ }^{[28,30,31,34,37]}$ The presence of impurities may enhance thermal stability because of classical reasons such as pinning of the grain boundaries due to the formation of second phase particles. ${ }^{[29-31]}$

Two mechanisms have been proposed for the stabilization of grain size in nanocrystalline materials, namely, the kinetic stabilization and the thermodynamic stabilization. The thermodynamic stabilization can be accomplished by addition of a solute which lowers the 
grain boundary energy ${ }^{[1,38-40]}$ as demonstrated in $\mathrm{Pd}-\mathrm{Zr}^{[41]}$ and $\mathrm{Fe}-\mathrm{Zr}^{[42]}$ systems. The kinetic stabilization operates via various mechanisms such as Zener drag and pinning of the grain boundaries by pores, inclusions, triple junctions or segregation of lower density solute at the grain boundaries. ${ }^{[24,26-28,43]}$ Excellent grain size stability, through kinetic stabilization, has been reported in literature mostly for $\mathrm{Cu}$ alloys containing elements which form an immiscible system with $\mathrm{Cu}$. An exemplary case of this has been demonstrated in $\mathrm{Cu}-\mathrm{W}$ thin films ${ }^{[4,45]}$ and $\mathrm{Cu}-\mathrm{Ta}$ system. ${ }^{[46]}$ In conclusion, one can say that alloying elements like $\mathrm{Zr}, \mathrm{Y}, \mathrm{W}, \mathrm{Nb}, \mathrm{Ta}$, etc., can be used to substantially decrease the grain growth susceptibility at high temperatures, thus enhancing the high temperature processibility as well as enabling higher temperature applications of such alloys.

\section{B. Synthesis of Nanocrystalline Alloys}

Several techniques have been employed for producing nanocrystalline solids in powder and thin film forms. The techniques of inert gas condensation, ${ }^{[3,47-50]}$ pulsed plasma deposition, ${ }^{[25]}$ and sputtering ${ }^{[48]}$ have exclusively been used for processing thin films or small amounts of nanocrystalline materials, whereas it is necessary to produce/process bulk samples for oxidation/corrosion or mechanical testing. Electrodeposition ${ }^{[33,34,51]}$ and severe plastic deformation ${ }^{[28-31,52-68]}$ have been recognized as the two relatively successful routes for processing thicker/larger sections of nanocrystalline metals and alloys. Pulsed electrodeposition has been employed successfully for processing nanocrystalline materials in bulk, ${ }^{[51]}$ most notably, Ni-Fe and Ni-Co alloys. ${ }^{[69,70]}$ However, synthesis of nanocrystalline alloys or metals by electrodeposition often requires use of additives for the purpose of biasing nucleation over growth of the depositing grains. These additives are believed ${ }^{[4]}$ to remain in the material as impurities and may cause poor mechanical properties (such as embrittlement), typically observed in nanocrystalline electrodeposits.

Among the plastic deformation techniques, advanced ball milling has produced artifact-free nanocrystalline powders. ${ }^{[71,72]}$ However, the ball-milled powders need to be compacted. Groza ${ }^{[73]}$ has reviewed various techniques employed for compaction of different nanocrystalline materials, viz., high pressure/lower temperature compaction, in situ consolidation, ${ }^{[74]}$ hot compaction ${ }^{[75]}$ explosive compaction, high pressure torsion (HPT),${ }^{[76,77]}$ equi-channel angular pressing (ECAP) ${ }^{[78-82]}$ equi-channel angular extrusion (ECAE). However, compaction of nanocrystalline $\mathrm{Fe}$ or Fe-based alloys may be a nontrivial task. The difficulties arise due to the restrictions on plastic deformation posed by the body centered cubic (BCC) structure causing high hardness. Such restrictions necessitate consolidation at high pressures/temperatures. For example, pure iron with an average grain size of $10 \mathrm{~nm}$ has a hardness of $10 \mathrm{GPa}^{\left[{ }^{[83]}\right.}$ Plastic deformation, a necessary condition for effective compaction requires the applied pressure to be in excess of the yield stress and approximately $1 / 3 \mathrm{rd}$ of the hardness (i.e., $3.5 \mathrm{GPa}$ ). The necessary plastic flow, high densifi- cation and inter-particle bonding can be achieved by compaction/sintering at high temperatures. However, processing at excessively high temperatures will commonly lead to grain growth, and loss of nanocrystalline structure.

Co-author Singh and his coworkers have successfully processed nanocrystalline $\mathrm{Fe}-\mathrm{Cr}$ alloy disks with closeto-theoretical density and without excessive grain growth. ${ }^{[84]}$ Nanocrystalline powder of $\mathrm{Fe}-10$ wt pet $\mathrm{Cr}$ alloy was produced by ball-milling, and the powder was compacted into disks by employing a suitable combination of prior thermal softening and compaction at a moderate temperature and pressure. To establish the suitable temperature for thermal softening without excessive grain growth, the authors studied the grain growth kinetics of the as-milled alloy powders in the temperature range $773 \mathrm{~K}$ to $973 \mathrm{~K}\left(500{ }^{\circ} \mathrm{C}\right.$ to $\left.700{ }^{\circ} \mathrm{C}\right)$ and the grain sizes were determined by $\mathrm{X}$-ray diffraction (XRD), after various intermittent durations. Figure 2 shows change in XRD patterns of $\mathrm{Fe}-10 \mathrm{Cr}$ alloy powder with increasing time of annealing at $873 \mathrm{~K}\left(600{ }^{\circ} \mathrm{C}\right)$. As shown in Figure 2, the diffraction line broadening of Bragg reflection peaks decreases as a result of the grain growth (grain size increases with the annealing time (Figure 3)). This pattern was consistent also at $773 \mathrm{~K}$ and $973 \mathrm{~K}\left(500{ }^{\circ} \mathrm{C}\right.$ and $\left.700{ }^{\circ} \mathrm{C}\right)$. However, grain growth is a strong function of temperature, as suggested from the increasing intensity of the initial grain growth with temperature (Figure 3). Initial grain growth is rapid at each of the three temperatures. The as-milled and annealed powder samples were compacted into pellets under a uni-axial pressure. It was necessary to reduce hardness of the powders, before subjecting them to a pressure compaction. Based on the grain growth data shown in Figure 3, a prior annealing at $873 \mathrm{~K}\left(600{ }^{\circ} \mathrm{C}\right)$ for 30 minutes was selected with a view to prior softening of the powder without any excessive grain growth. The prior annealing at $873 \mathrm{~K}\left(600{ }^{\circ} \mathrm{C}\right)$ for 30 minutes though would result in some grain growth (as suggested in Figure 3), the grain size of the alloy was still found to be $42 \mathrm{~nm}$ which is well within the nanocrystalline regime. Most importantly, because of the softening caused by the prior annealing it was possible to compact the powder into pellets/disks (diameter $=12 \mathrm{~mm}$, thickness $=1.5 \mathrm{~mm}$ ) at the room

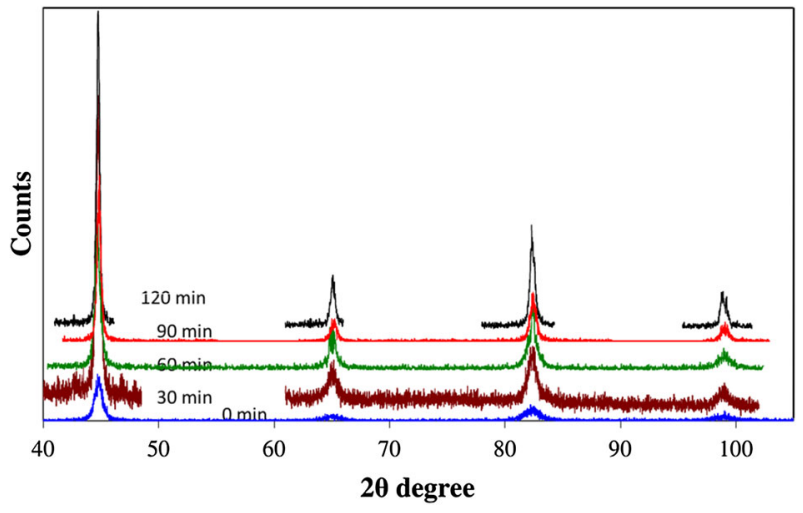

Fig. 2-XRD profiles for ball-milled nanocrystalline $\mathrm{Fe}-10 \mathrm{Cr}$ alloy annealed at $873 \mathrm{~K}\left(600{ }^{\circ} \mathrm{C}\right)$ for different time periods. ${ }^{[106]}$ 


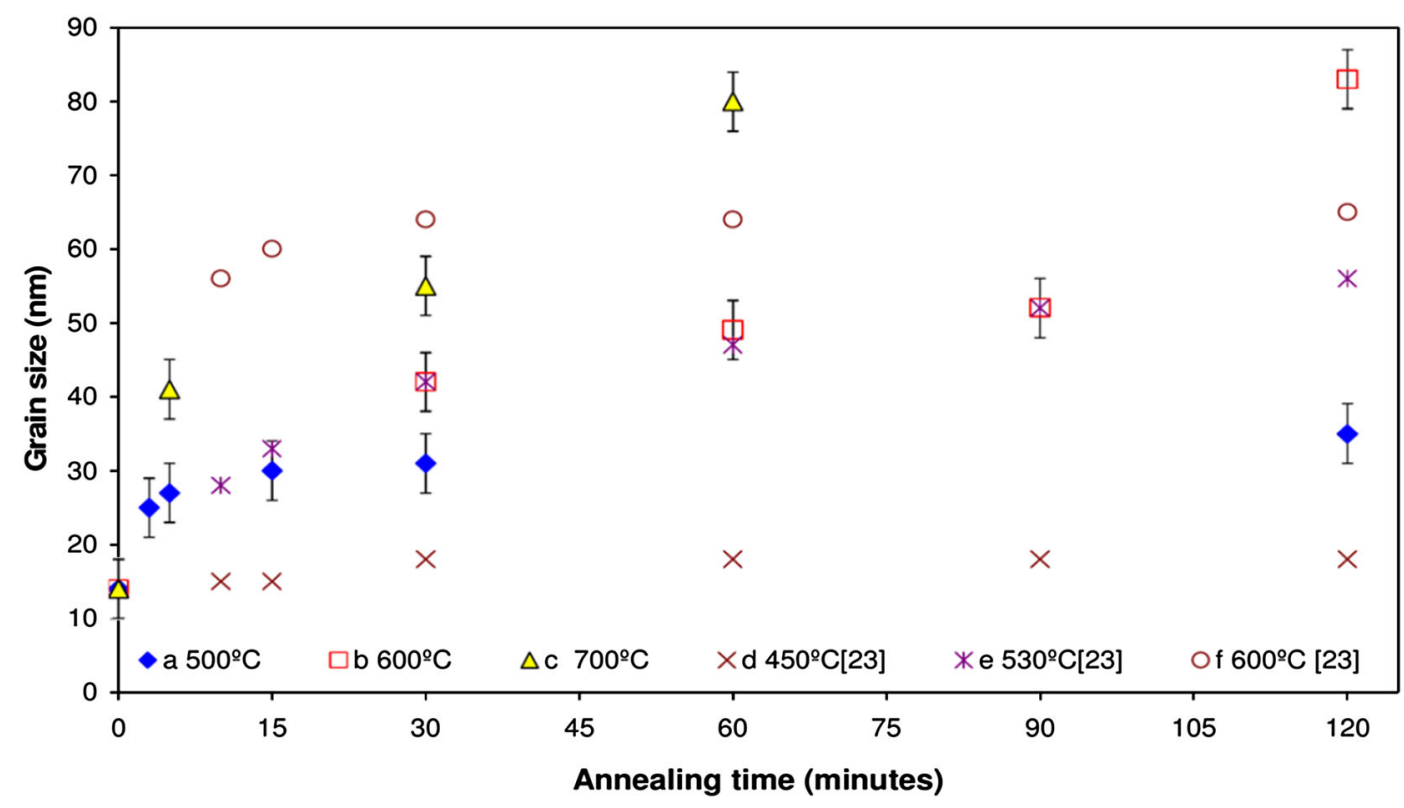

Fig. 3 - Grain growth in Fe-10Cr nanocrystalline alloy at $773 \mathrm{~K}, 873 \mathrm{~K}$, and $973 \mathrm{~K}\left(500{ }^{\circ} \mathrm{C}, 600{ }^{\circ} \mathrm{C}\right.$, and $\left.700{ }^{\circ} \mathrm{C}\right) .{ }^{[106]}$

temperature employing a pressure of $3 \mathrm{GPa}$. Compacted pellets were sintered for 1 hour at $873 \mathrm{~K}\left(600{ }^{\circ} \mathrm{C}\right)$, which further improved the density (close to $100 \mathrm{pct}$ of the theoretical density). Though the sintering caused some further grain growth, the grain size of the sintered pellets was determined to be $52 \pm 4 \mathrm{~nm}$. At each stage (compaction and sintering), the grain size was determined by diffraction line broadening (as shown in Figure 2).

A few other techniques have been employed for consolidation into bulk nanocrystalline Fe-based alloys, such as shockwave sintering proposed by Jain and Christman, ${ }^{[85]}$ self-propagating high temperature synthesis (SHS) proposed by $\mathrm{Fu}$ et al., ${ }^{[86]}$ arc-plasma sintering proposed by Lee and $\mathrm{Kim}^{[87]}$ and spark plasma sintering (SPS) which is generally used for glassy alloys and multicomponent nanocrystalline alloys. ${ }^{[88-90]}$ However, apart from the SHS, other sophisticated techniques have limitations on size and are not viable for up-scaling.

As mentioned earlier, the IC forms a significant proportion of the nanostructured matrix. The variation in the processing technique significantly affects the nature of the interface/grain boundary between the crystallites. ${ }^{[91]}$ These interfaces (grain boundaries, triple junctions, quadruple nodes, etc.) are assumed to play a significant role in controlling the macroscopic properties of the sample ${ }^{[12,24,27,92]}$ and may also be relevant for corrosion resistance. It has been established in literature on different systems that if the crystallites of two nanocrystalline materials of same element/compound have comparable size, chemical composition, etc., the properties of the two may still vary depending on their interfacial structure. ${ }^{[91]}$ For example, nanocrystalline $\mathrm{Ni}$ having an average grain size of $10 \mathrm{~nm}$ and density of about 94 pct, prepared by consolidation of pure $\mathrm{Ni}$ powder (that was obtained by inert gas condensation technique) exhibited very little ( $<3$ pct) ductility whereas nanocrystalline $\mathrm{Ni}$ (similar grain size and chemical composition) obtained by means of electro-deposition could be deformed extensively ( $>100$ pct). ${ }^{[24]}$ Therefore, there have been numerous studies conducted on the structural characteristics of interfaces in nanocrystalline materials, prepared using different synthesis routes. Studies on nanocrystalline Pd by Löffler and Weissmül$\operatorname{ler}^{[93]}$ and on nanocrystalline $\mathrm{Ni}_{3} \mathrm{Fe}$ by Fraze et al. ${ }^{[94]}$ have established that after subjecting the nanocrystalline samples to consolidation, aging and annealing treatments under different conditions, the relaxed (equilibrium) grain boundaries are rather similar to those of their coarse-grained counterparts, whereas the unrelaxed (non-equilibrium) grain boundaries are significantly different as compared to the grain boundaries in microcrystalline alloys. In spite of these studies, there still remains a lot to be understood about the interfaces in nanocrystalline materials. ${ }^{[24,27,92,95-97]}$ Apart from the difference in the structure of inter-crystalline region, caused by the different processing techniques, there is evidently a marked deviation from the equilibrium state of the lattice structure (crystalline component) of the nanostructured materials as well. Quantitative XRD and Mössbauer spectroscopy have been used to study the changes from equilibrium condition, in the lattice parameters of the nanometer sized crystallites produced by various synthesis routes. ${ }^{[98]}$ Table I shows the changes in lattice parameter and static Debye-Waller parameter (DWP) for various metals/alloys processed by different techniques. ${ }^{[98]}$ The deviation from equilibrium, classified as distorted lattice structures in pure elements and stoichiometric line compounds and the formation of metastable phases below a critical crystallite size, have been dealt in detail by Murthy et al. in their review. ${ }^{[91]}$ 
Table I. Parameter Changes $\Delta a=\left(a-a_{0}\right) / a_{0}$ and $\Delta c=\left(c-c_{0}\right) / c_{0}$ and the Static DWP Changes $\Delta \boldsymbol{B}_{\mathrm{s}}=\left(\boldsymbol{B}_{\mathrm{s}}-\boldsymbol{B}_{\mathrm{s}_{0}}\right) / \boldsymbol{B}_{\mathrm{s}_{0}}$ in Various Nanocrystalline Materials Processed by Different Techniques ${ }^{[98]}$

\begin{tabular}{lccccc}
\hline & & & \multicolumn{3}{c}{ Lattice Distortion } \\
\cline { 4 - 6 } Sample & $d(\mathrm{~nm})$ & $\begin{array}{c}\text { Synthesis } \\
\text { Route* }\end{array}$ & $\Delta a(\mathrm{pct})$ & $\Delta c$ (pct) & $\Delta B_{\mathrm{s}}$ (pct) \\
\hline $\mathrm{Cr}$ & 11 & UFP & 0.04 & - & 230 \\
$\mathrm{Fe}$ & 8 & $\mathrm{BM}$ & 0.09 & - & 110 \\
$\mathrm{Cu}$ & 11 & $\mathrm{BM}$ & 0.06 & - & - \\
$\mathrm{Cu}$ & 27 & $\mathrm{ED}$ & 0.06 & - & - \\
$\mathrm{Pd}$ & 8 & UFP & 0.04 & - & 220 \\
$\mathrm{Si}$ & 8 & $\mathrm{BM}$ & 0.2 & - & - \\
$\mathrm{Ge}$ & 4 & $\mathrm{BM}$ & 0.2 & - & - \\
$\mathrm{Se}$ & 13 & $\mathrm{CL}$ & 0.3 & -0.12 & 900 \\
$\mathrm{Se}$ & 14 & $\mathrm{BM}$ & 0.15 & -0.01 & - \\
$\mathrm{Ni}_{3} \mathrm{P}$ & 7 & $\mathrm{CL}$ & 0.21 & -0.13 & - \\
$\mathrm{Fe}_{2} \mathrm{~B}$ & 23 & $\mathrm{CL}$ & 0.2 & -0.23 & - \\
\hline
\end{tabular}

*BM: ball milled; UFP: ultrafine powder consolidation; ED: electrodeposition; CL: crystallization from amorphous solids.

\section{CORROSION/OXIDATION OF NANOCRYSTALLINE METALS AND ALLOYS}

Common approaches for enhancing the corrosion resistance of metals/alloys include addition of such alloying element(s) that can form a passive surface layer, use of inhibitors, application of protective coatings and microstructure modification. ${ }^{[99-105]}$ Exploitation of nanocrystalline structure has recently been investigated for an improvement in both electrochemical corrosion as well as high temperature oxidation of various alloys. Recent studies have shown that the effect of reducing the grain size to nanocrystalline regime can significantly improve the high temperature oxidation resistance of Fe-based alloys due to the enhanced diffusion of beneficial alloying elements to the alloy surface facilitating the formation of a protective oxide layer. ${ }^{[8,106]}$ Most metals/alloys are thermodynamically reactive in various environments like polluted water, saline, acidic or alkaline solutions. ${ }^{[104,105]} \mathrm{A}$ metal/alloy when exposed to a corrosive environment can undergo active dissolution, passivation or localized corrosion. The effect of nanocrystalline structure on high temperature oxidation and aqueous corrosion of different alloys is discussed here in detail.

Degradation of most metals due to an aggressive environment is a result of their thermodynamic instability in the elemental form, whereas the progress of corrosion reaction is largely governed by either one or a combination of the following phenomena:

- Electrochemical non-homogeneity at the metal surface, and

- Diffusion of elemental/ionic species: (i) in the metal substrate and/or, (ii) through the layer of corrosion product or through the electrolytic environment immediately adjacent to the metal surface.

The nanocrystalline structure can remarkably influence the nature and/or degree of both electrochemical inhomogeneity at the surface and diffusion in the bulk of metals. Besides, there may be other influences of the nanocrystalline structure (the degree of which will vary from metal to metal). For example, the structure (such as grain size) and associated properties (such as mechanical property, structure, nucleation and growth, defect density etc.) of the corrosion films developed on nanocrystalline substrate may be considerably different from those on a microcrystalline substrate. Thus, a nanocrystalline structure of the metal influencing the structure of the corrosion films can also indirectly influence diffusion through the layer of corrosion film.

\section{AQUEOUS CORROSION}

There has been a split of opinions among the researchers about the effect of nanocrystalline structure on the corrosion of materials. Early fundamental studies on the role of nanostructure in electrochemical corrosion were carried out on $\mathrm{Co},{ }^{[107-109]} \mathrm{Cu}^{[107,110-112]} \mathrm{Ni}^{[10,113-116]}$ and Ni-based binaries. ${ }^{[9,117-119]}$ Traditionally, it is believed that electrochemical inhomogeneity at the metal surface due to the excess of high energy areas with much greater degree of disorder like grain boundaries and triple junctions (such as those in the case of the nanocrystalline materials), can make these materials more anodic. ${ }^{[11,120-122]}$ So, in simplistic terms, the corrosion rate of a material in nanocrystalline state should be much higher as compared to that in its microcrystalline form. Some experimental evidences have supported this view $^{[10,117,121,122]}$ while majority have shown contradictory behavior. ${ }^{[16,123-125]}$ This section will first list a few of the studies on different alloy systems and then subsequently summarize the common characteristics which govern the corrosion in nanocrystalline materials.

\section{A. Ni-Based Alloy Systems}

Early studies on nanocrystalline pure-Ni suggested deterioration in passivation behavior due to reduction in grain size. Rofagha et al.$^{[9,10]}$ compared the electrochemical corrosion of nanocrystalline $\mathrm{Ni}$ (grain sizes 32, 50, and $500 \mathrm{~nm}$ ) with that of coarse-grained pure $\mathrm{Ni}$ (grain size $100 \mu \mathrm{m}$ ) in de-aerated $2 \mathrm{~N} \mathrm{H}_{2} \mathrm{SO}_{4}$ solution. The study showed that although the nano- and microcrystalline $\mathrm{Ni}$ had similar active, passive and transpassive behavior, the current density in the passive region was higher in the case of nanocrystalline $\mathrm{Ni}$, suggesting their higher corrosion rates, ${ }^{[9,10]}$ as shown in Figure 4. Also, the open circuit potential (OCP) of the nanocrystalline $\mathrm{Ni}$ was found to be considerably nobler. Figure 5 shows scanning electron micrographs of nickel with nanocrystalline $(32 \mathrm{~nm})$ and microcrystalline grain sizes $(100 \mu \mathrm{m})$ that were held potentiostatically at $1200 \mathrm{mV}$ (SCE) in $2 \mathrm{~N}$ $\mathrm{H}_{2} \mathrm{SO}_{4}$ solution for 2000 seconds. ${ }^{[10]}$ Although both the specimens suffered extensive corrosion, it can be seen from the SEM images that the nanocrystalline $\mathrm{Ni}$ is more uniformly corroded while the specimen with $100 \mu \mathrm{m}$ grain size shows extensive localized attack along the grain boundaries and triple junctions. The authors have concluded with the aid of X-ray photoelectron spectroscopy that the passive film formed on nanocrystalline $\mathrm{Ni}$ 


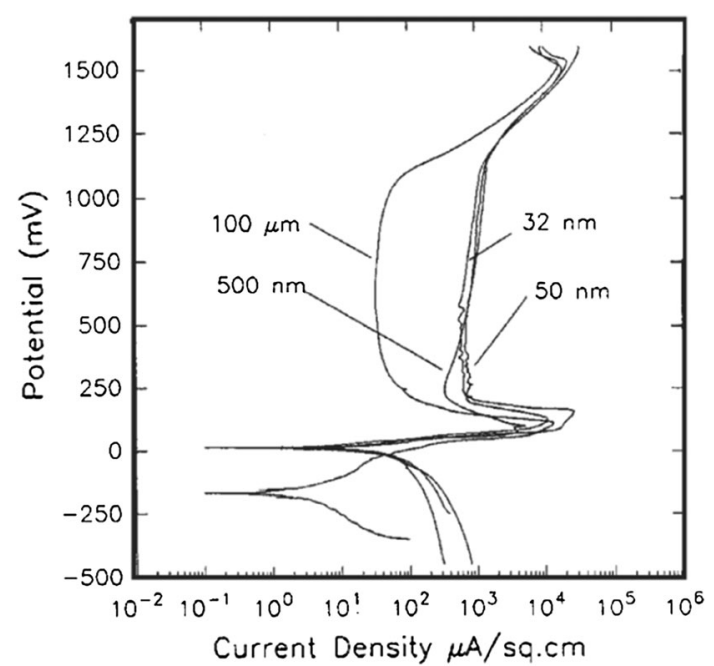

Fig. 4-Potentiodynamic polarization curves for nanocrystalline and microcrystalline $\mathrm{Ni}$ in $2 \mathrm{~N} \mathrm{H}_{2} \mathrm{SO}_{4}$ at ambient temperature. ${ }^{[10]}$

had more defects than that on the microcrystalline $\mathrm{Ni}$ which suggests the breakdown sites of the passive film to be more uniformly distributed, and hence, a more uniform corrosion in case of the former. ${ }^{[10]}$ In contrast, in case of coarse-grained $\mathrm{Ni}$, the breakdown of the passive film occurs first at the grain boundaries and triple junctions rather than the crystal surface, leading to preferential attack at these defects.

Similar observations were made by Kim et al. ${ }^{[126]}$ who compared the effect of grain size and sulfur solute segregation on the corrosion characteristics of nanocrystalline $(20$ to $30 \mathrm{~nm})$ and polycrystalline $(100 \mu \mathrm{m})$ electrodeposited $\mathrm{Ni}$, in $0.25 \mathrm{M} \mathrm{Na}_{2} \mathrm{SO}_{4}$ solution at a $\mathrm{pH}$ of 6.5. The sulfur impurity in both cases was controlled at $1000 \mathrm{ppm}$ (by wt.). Despite the remarkable similarity in the potentiodynamic polarization curves for nc and mc alloys, there was a significant difference in their corrosion morphologies. As seen in Figure 6, the nanocrystalline Ni exhibited shallow pitting $(<2 \mu \mathrm{m})$ distributed evenly over the surface, whereas the polycrystalline $\mathrm{Ni}$ suffered extensive intergranular attack along the grain boundaries (as deep as $100 \mu \mathrm{m}$ ).

The effect of nanocrystalline grain size in Ni-based alloys is more pronounced in certain aggressive environments. It has been shown by Liu et al. ${ }^{[116]}$ that the nanocrystalline grain size can enhance the corrosion resistance in chloride containing acidic environments. The potentiodynamic polarization curves for Ni-based nanocrystalline superalloy coating and cast superalloy, in $0.25 \mathrm{M} \mathrm{Na} \mathrm{SO}_{4}+0.05 \mathrm{M} \mathrm{H} \mathrm{H}_{2} \mathrm{SO}_{4}$ and $0.5 \mathrm{M}$ $\mathrm{NaCl}+0.05 \mathrm{M} \mathrm{H}_{2} \mathrm{SO}_{4}$ solutions are shown in Figure 7. In the acidic $\mathrm{Na}_{2} \mathrm{SO}_{4}$ solution, the nanocrystalline coating and the cast alloys showed similar passivation behavior, $E_{\text {corr }}$ and breakdown potentials. The passivation current density $i_{\text {pass }}$ was slightly higher for the nanocrystalline coating, and subsequently, the coating was found to be less stable than the cast alloy. However, in the acidic chloride solution, the electrochemical behavior of the two alloys was remarkably different. The nanocrystalline coating showed an extended passive

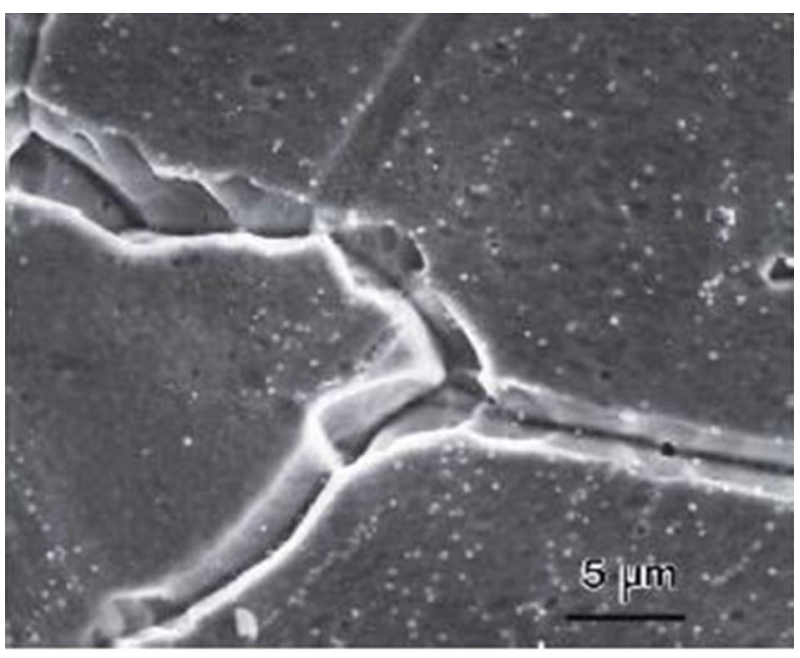

(a)

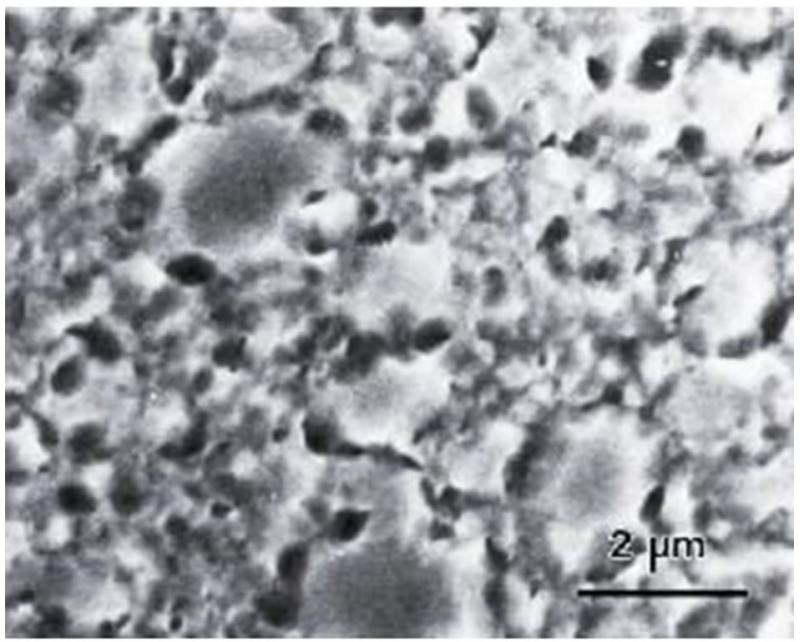

(b)

Fig. 5-SEM micrographs showing $\mathrm{Ni}$ with (a) $100 \mu \mathrm{m}$ and (b) $32 \mathrm{~nm}$ grain size held at a constant potential of $1.2 \mathrm{~V}$ (SCE) in $2 \mathrm{~N}_{2} \mathrm{SO}_{4}$ for 2000 s. $^{[10,146]}$

region with the passivation potential being much more positive and the passivation current density was an order of magnitude lower for the nanocrystalline coating, thus substantiating that the finer grain size alloy was less susceptible to degradation in a chloride environment. The reduced susceptibility to localized corrosion was attributed to the fine grained structure which allows a more uniform distribution of $\mathrm{Cl}^{-}$ions, thereby the condition for a localized attack was less favorable.

\section{B. Fe-Based Alloy Systems}

Effect of nanocrystalline structure on corrosion of Fe-based alloys has primarily focussed on low carbon steels (LCSs), stainless steels and Fe-10Cr alloys. Since the Cr-concentration of the Fe-alloy is known to significantly affect the corrosion property of steel, we will categorize the corrosion in nanocrystalline Fe-based alloys in these three categories-low-carbon steel $(\mathrm{Cr}<1 \mathrm{pct}), \mathrm{Fe}-10 \mathrm{Cr}(10 \mathrm{wt}$ pet $\mathrm{Cr})$ and high $\mathrm{Cr}$ 

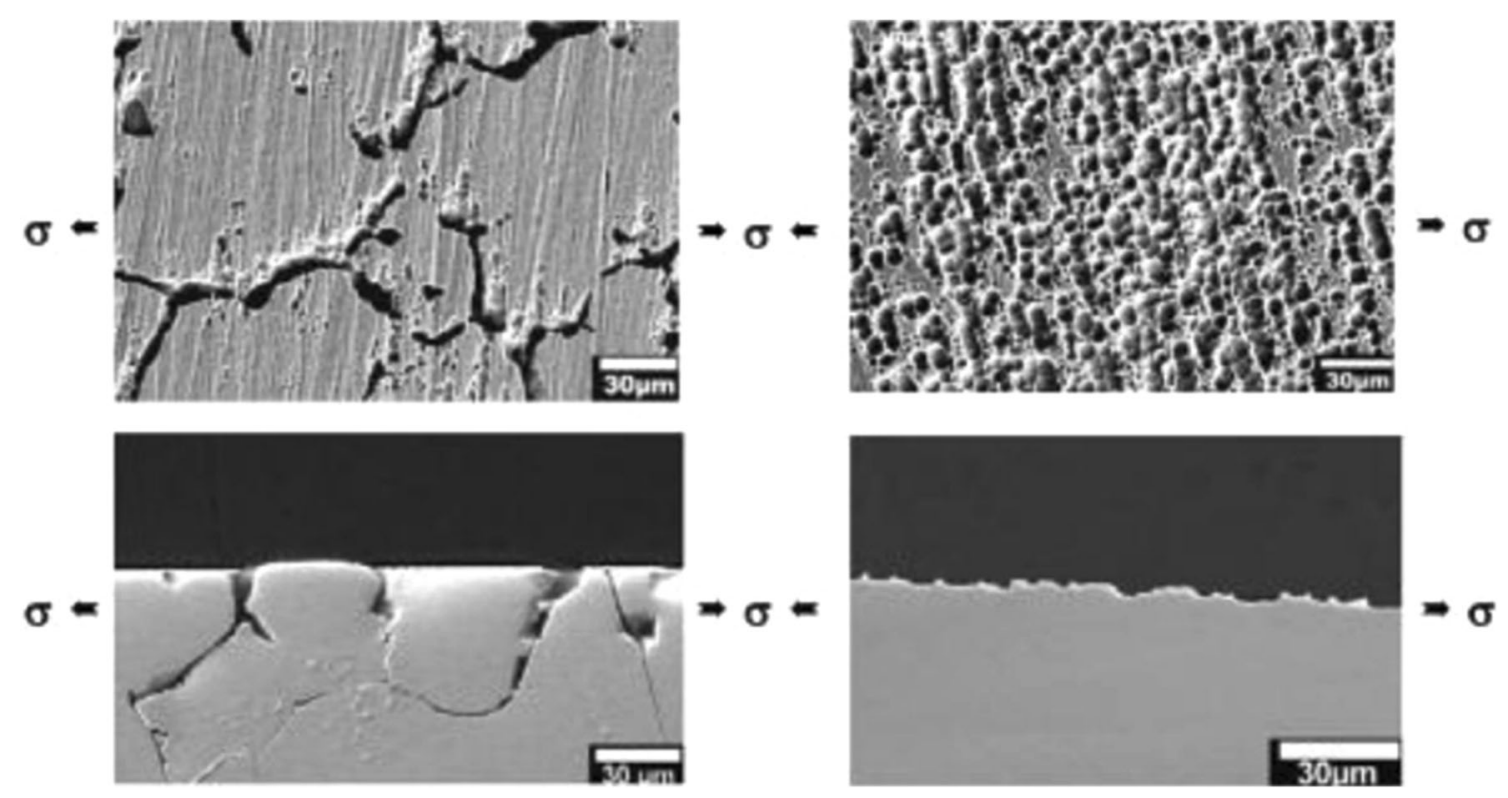

Fig. 6-SEM micrographs showing surface (top) and cross-sectional (bottom) corrosion morphologies of microcrystalline (left) and nanocrystalline (right) Ni containing $1000 \mathrm{ppm}$ sulfur impurity. Sigma $(\sigma)$ indicates the internal or externally applied stress. ${ }^{[117]}$

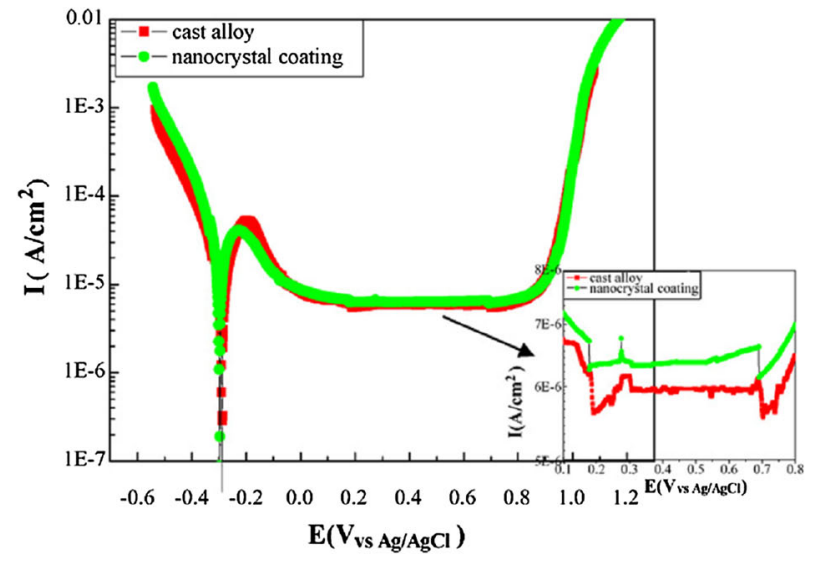

(a)

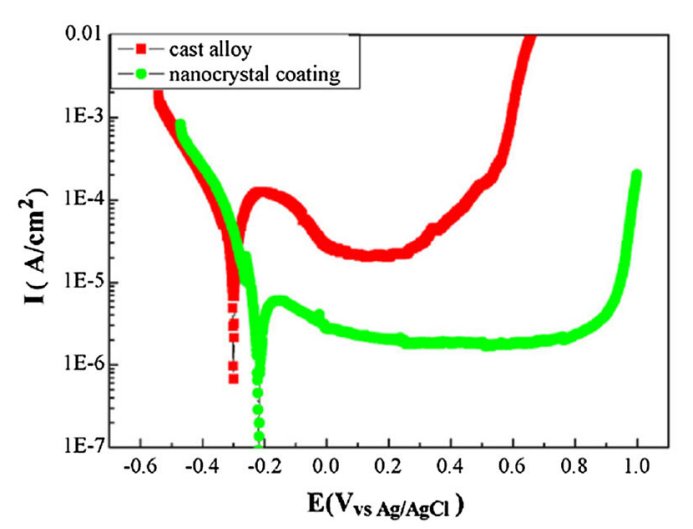

(b)

Fig. 7-Potentiodynamic polarization for Ni-based cast superalloy and nanocrystalline coating in $(a) 0.25 \mathrm{M} \mathrm{Na} \mathrm{NO}_{4}+0.05 \mathrm{M} \mathrm{H}_{2} \mathrm{SO}_{4}$ solution $(b) 0.5 \mathrm{M} \mathrm{NaCl}+0.05 \mathrm{M} \mathrm{H}_{2} \mathrm{SO}_{4}$ solution. ${ }^{[16]}$ stainless steels (like SS304, SS310, SS316 etc., with Cr content $>18 \mathrm{wt} \mathrm{pct})$. The effect of more aggressive electrolytes (those containing $\mathrm{Cl}^{-}$ions) and $\mathrm{Fe}-\mathrm{Al}$ alloys will also be discussed subsequently.

Li et al. ${ }^{[127]}$ have shown that the corrosion behavior of LCS, surface modified using ultrasonic shot peening (USSP), had a distinct correlation to grain size. For alloys having surface grain size $>35 \mathrm{~nm}$, the electrochemical corrosion behavior had no significant difference whereas in case of surface grain size $<35 \mathrm{~nm}$, the rate of corrosion increased with a decrease in grain size. Similarly, the study by Oguzie et al. ${ }^{[28]}$ corroborates this observation. The study showed that the corrosion resistance of a nanocrystalline LCS produced by magnetron sputtering was inferior to conventional steel with same composition. ${ }^{[128]}$

In contrast to the above observations on LCS, Gupta et al. ${ }^{[124,129]}$ observed that the corrosion resistance of chromium containing $\mathrm{Fe}$-alloys $(\mathrm{Fe}-10 \mathrm{Cr})$ improved due to a nano-scale structure. The passive film, characterized by XPS, on nanocrystalline alloy showed the presence of a Cr-rich phase whereas the conventional grain-sized alloy lacked the ability to form a Cr-rich phase. Another evidence for the improved corrosion resistance of nanocrystalline $\mathrm{Fe}-10 \mathrm{Cr}$ was established by Meng et al. ${ }^{[130]}$ who have compared the electrochemical corrosion behavior of DC magnetron sputtered nanocrystalline $\mathrm{Fe}-10 \mathrm{Cr}$ coating on glass substrates with that of $\mathrm{Fe}-10 \mathrm{Cr}$ cast alloy, in $0.05 \mathrm{M} \mathrm{H} \mathrm{H}_{2} \mathrm{SO}_{4}+0.25 \mathrm{M}$ $\mathrm{Na}_{2} \mathrm{SO}_{4}$ solution. The polarization curves in Figure 8 indicate somewhat higher $i_{\text {corr }}$ for the nanocrystalline coating, but also considerably lower $i_{\max }$ and $i_{\text {pass }}$ as compared to the cast alloy. For the nanocrystalline $\mathrm{Fe}-10 \mathrm{Cr}$ coating, although the corrosion was accelerated in the active dissolution regime, the passivation ability 


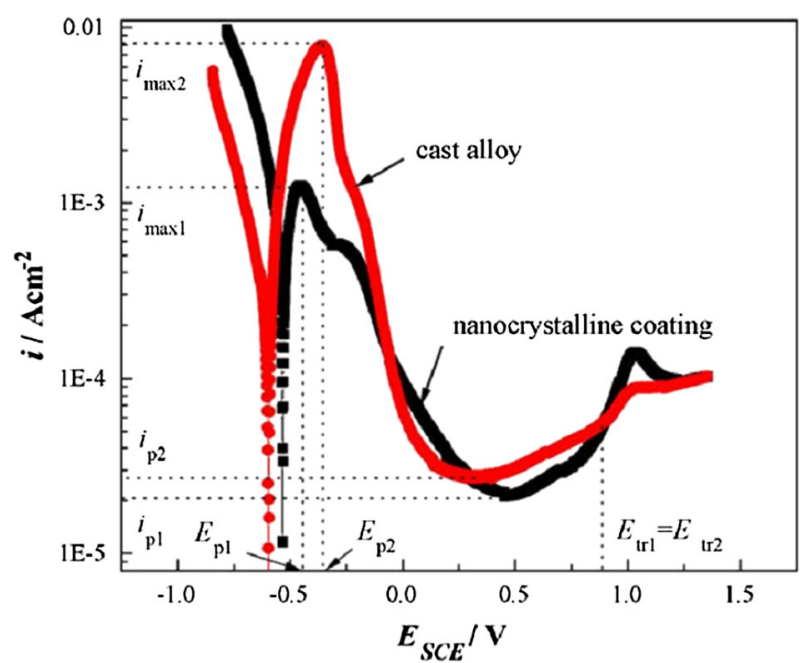

Fig. 8-Potentiodynamic polarization curves $\mathrm{Fe}-10 \mathrm{Cr}$ nanocrystalline coating and cast alloy in $0.05 \mathrm{M} \mathrm{H} \mathrm{H}_{2} \mathrm{SO}_{4}+0.25 \mathrm{M} \mathrm{Na} \mathrm{NO}_{4}$ solution. ${ }^{[130]}$

and stability of the passive film were improved as compared to the cast alloy. The authors have attributed this behavior to faster diffusion of $\mathrm{Cr}$ in the passive film due to large volume fraction of grain boundaries, which act as the short-cut diffusion paths for $\mathrm{Cr}$ to the surface, hence facilitating passivation. The claimed role of diffusion in enhancing aqueous corrosion resistance of stainless steel at low temperatures, as suggested in literature ${ }^{[102,130]}$ has received a strong criticism in a very recent report ${ }^{[124]}$ on the basis of the very low diffusivities (i.e., $10^{-40}$ to $10^{-43} \mathrm{~m}^{2} / \mathrm{s}$ ) at the test temperatures.

A few studies ${ }^{[102,130-133]}$ have also compared the electrochemical corrosion of nanocrystalline and microcrystalline alloys with high $\mathrm{Cr}$ contents $(>18 \mathrm{wt}$ pct). Electrochemical corrosion resistance of a nanocrystalline surface of 316 stainless steel developed by surface mechanical attrition treatment (SMAT) was found to be considerably inferior to the microcrystalline unmodified bulk. This behavior was attributed to the considerable increase in the 'fast diffusion channels' for ions, i.e., grain boundaries and triple junctions in the nanocrystalline material. ${ }^{[131]}$ In a similar study, the corrosion resistance of nanocrystalline 309 stainless steel coating developed by DC magnetron sputtering (DCMS) (grain size $<50 \mathrm{~nm}$ ) was compared with bulk 309 stainless steel in $0.25 \mathrm{M} \mathrm{Na}_{2} \mathrm{SO}_{4}+0.05 \mathrm{M} \mathrm{H}_{2} \mathrm{SO}_{4}$ (Figure 9). ${ }^{[133]}$ In the $\mathrm{Na}_{2} \mathrm{SO}_{4}$ solution, there was a difference in the active and active-passive transition behavior of the nanocrystalline coating and bulk alloy, but the overall span of the passive region and the transpassive potentials were quite similar. The authors have attributed the improved localized corrosion resistances to the surface homogeneity and finer grain size in case of the nanocrystalline coating, whereas high resistance to breakdown of the passive film by sulfate ion in case of bulk alloy. Based on the above evidences, a definite trend can be observed. The role of grain size in corrosion of $\mathrm{Fe}-\mathrm{Cr}$ alloys depends strongly on the bulk $\mathrm{Cr}$ content. If the $\mathrm{Cr}$ content is high enough for the formation of a Cr-rich passive film then the corrosion resistance improves (as

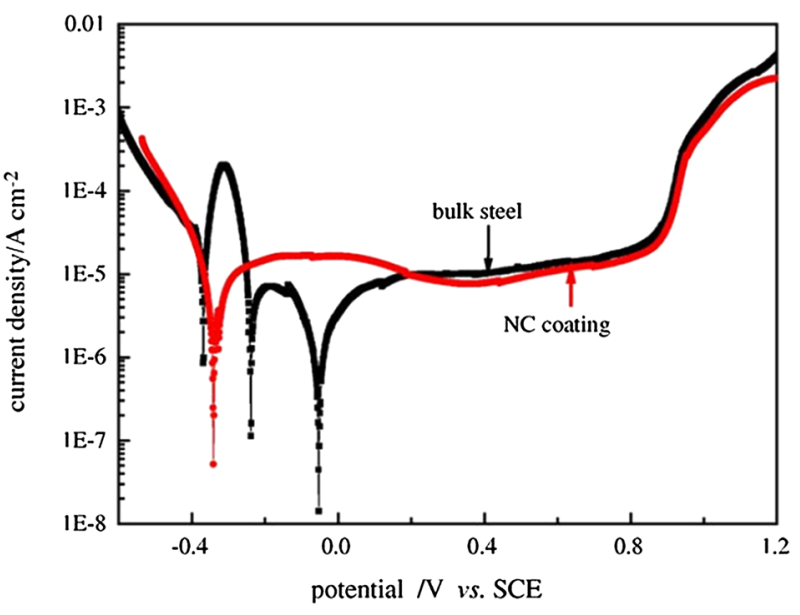

(a)

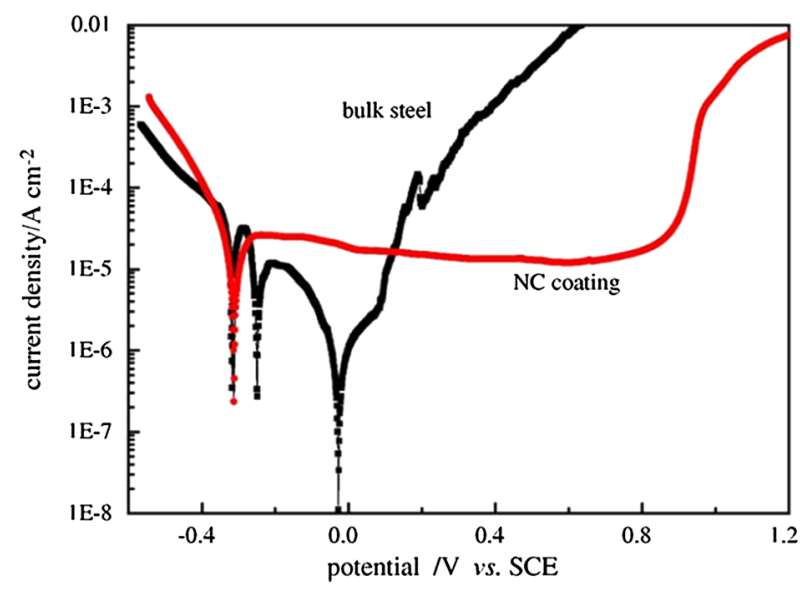

(b)

Fig. 9-Potentiodynamic polarization for 309SS cast alloy and nanocrystalline coating in (a) $0.25 \mathrm{M} \mathrm{Na} \mathrm{SO}_{4}+0.05 \mathrm{M} \mathrm{H}_{2} \mathrm{SO}_{4}$ solution, (b) $0.5 \mathrm{M} \mathrm{NaCl}+0.05 \mathrm{M} \mathrm{H}_{2} \mathrm{SO}_{4}$ solution. . $^{[33]}$

seen in $\mathrm{Fe}-10 \mathrm{Cr}$ alloys and stainless steels). However, as evidenced in LCSs, the corrosion rate increases with grain-refinement in Cr-deficient alloys which fail to form a passive film. The governing mechanism for such a trend is discussed later in the article.

It would be interesting to note whether such a trend is also observed in aluminum and silicon containing $\mathrm{Fe}-$ Alloys. $\mathrm{Ji}$ et $a l^{[134]}$ have compared the corrosion behavior of nanocrystalline high-velocity oxy-fuel (HVOF) FeAl coatings with that of extruded Fe-Al alloy (Figure 10). Though both HVOF coatings and extruded alloy showed similar active-passive and transpassive behavior, with the passive region consisting of two domains, the higher $i_{\text {corr }}$ and $i_{\text {pass }}$ for the HVOF coatings suggested their inferior corrosion resistance. However, this comparison may not be quite formidable since the nanocrystalline coatings had over 6 to 8 pct porosity which increases the effective surface area in contact with the solution (in contrast to the extruded bulk alloy that had negligible porosity). Secondly, the compositions of the coating and the extruded alloy are not comparable because of the presence of a 


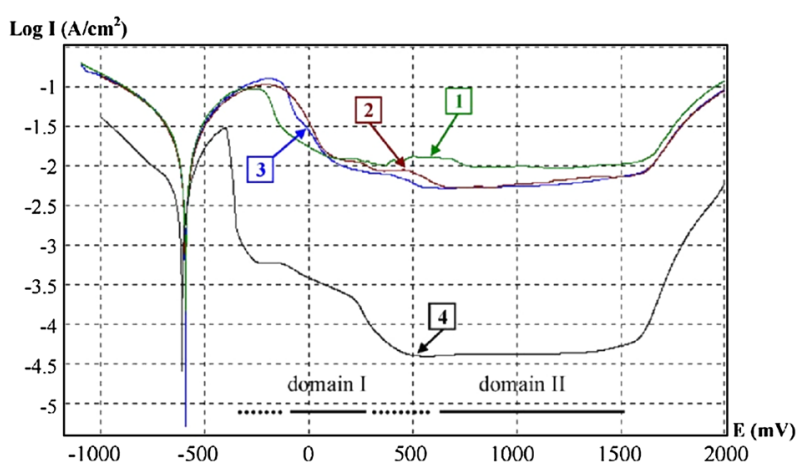

Fig. 10-Potentiodynamic polarization curves for three HVOF coatings (curves 1, 2, 3) and an extruded FeAl alloy (curve 4). ${ }^{[134]}$

considerable amount of Fe-Al oxides (over 13 pct) in the nanocrystalline coating. Therefore, it is possible that the decrease in corrosion resistance is not due to the nanocrystalline structure of the coating. This argument is supported by another study on Fe-Al alloy, ${ }^{[135]}$ which showed the nanocrystalline Fe-8Al alloy to improve corrosion resistance. Similar trend has also been shown for Fe-Si nanocrystalline alloys. ${ }^{[136]}$

El-Moneim et al. ${ }^{[137-139]}$ have studied the electrochemical corrosion behavior of nc (grain size: 100 and $600 \mathrm{~nm}$ ) Nd-Fe-B magnets in $0.1 \mathrm{M} \mathrm{H}_{2} \mathrm{SO}_{4}$ solution by inductively coupled plasma (ICP) solution analysis, gravimetric and electrochemical techniques and hot extraction $[\mathrm{H}]$-analysis. ${ }^{[137]}$ The $\mathrm{Nd}-\mathrm{Fe}-\mathrm{B}$ magnet specimens were immersed in an $\mathrm{N}_{2}$-purged acid solution and the dissolution rate was monitored in situ using ICP. Figure 11(a) shows the coarser grained material to exhibit superior corrosion resistance as compared to the hot pressed sample with $100 \mathrm{~nm}$ grain size. The gravimetric analysis (Figure 11(b)) results have also suggested inferior corrosion resistance for finer grain size material. This behavior has been attributed to the increase in intergranular corrosion due to the increase in the grain boundary volume fraction of the refined structure (the volume fraction of the Nd-rich intergranular phase is significantly increased after nanocrystallization).

Chloride ions have profound influence in disruption of passive films that develop on stainless steels, and thereby, compromise the corrosion resistance of such alloys. Wang and $\mathrm{Li}^{[102]}$ have reported superior corrosion resistance of surface nanocrystalline 304 stainless steel (prepared by sandblasting and annealing process), in 3.5 pet $\mathrm{NaCl}$ solution. In another study, a nanocrystalline coating of 304-stainless steel (25 nm grain size) is reported to show superior corrosion resistance to the bulk microcrystalline alloy of same composition in chloride containing acidic medium. ${ }^{[99]}$ The coating not only exhibited a wider passivation region but also showed no evidence of pitting. In contrast, the bulk steel suffered extensive pitting corrosion. The nanocrystalline coating and the bulk alloy had different lattice structures (ferritic and austenitic, respectively), this difference cannot explain the greater resistance of nc coating to pitting since ferritic stainless steels usually exhibit lower breakdown potentials as compared to their

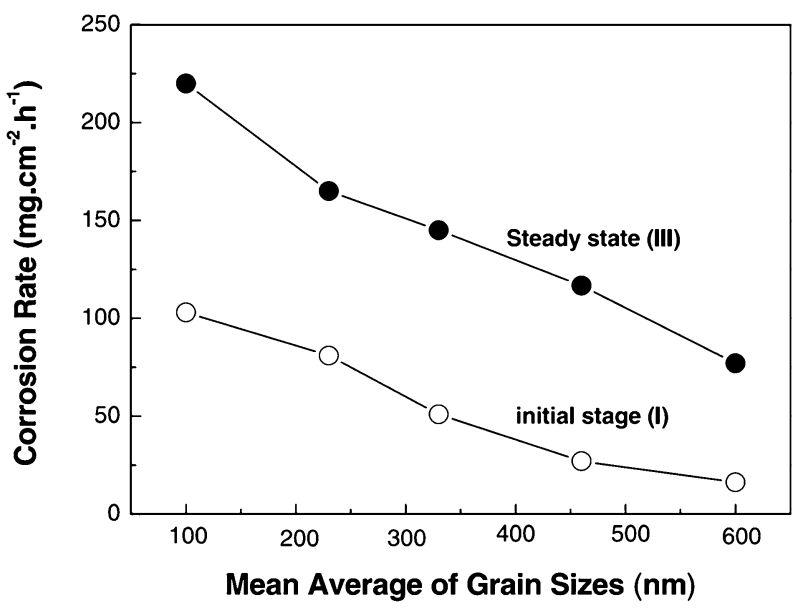

(a)

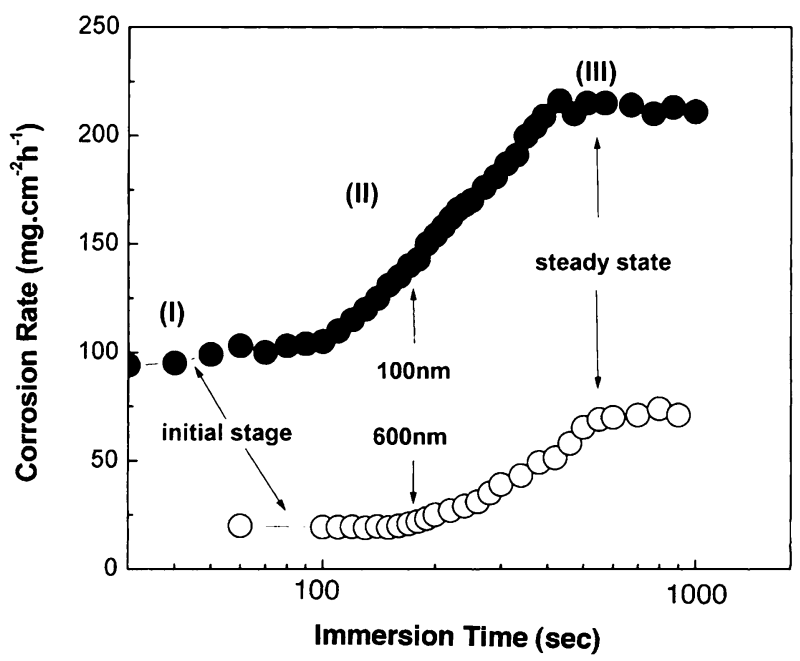

(b)

Fig. 11-(a) Corrosion rates of $\mathrm{NdFeB}$ magnets having grain sizes 100 and $600 \mathrm{~nm}$ measured by ICP solution analysis as a function of immersion time. (b) Corrosion rates of the magnets measured by gravimetric analysis after 1 and $10 \mathrm{~min}$ as a function of mean average grain size. ${ }^{[137,138]}$

austenitic counterparts with similar $\mathrm{Cr}$ content. Consequently, the authors have attributed the observed improvement to the nanocrystalline grain size of the coatings.

\section{Other Nanocrystalline Metals and Alloys}

A recent study ${ }^{[125]}$ on nanocrystalline $\mathrm{Cu}$ coatings deposited on a silica substrate showed the $\mathrm{Cu}$ coatings (grain size 40 and $90 \mathrm{~nm}$ ) to possess much improved resistance to aqueous corrosion in $0.1 \mathrm{M} \mathrm{NaOH}$ solution as compared to a conventional $\mathrm{Cu}$ sheet (as evident from the potentiodynamic polarization scans and Nyquist plots shown in Figure 12). An improvement in the corrosion characteristics due to nanocrystalline structure has also been reported in the case of $\mathrm{Cu}-20 \mathrm{Zr}$ and $\mathrm{Cu}-70 \mathrm{Zr}$ alloys, ${ }^{[140,141]}$ and pure- $\mathrm{Cu}$ synthesized by accumulative roll bonding process and having different grain sizes. ${ }^{[142]}$ Moreover, the extent of localized corro- 

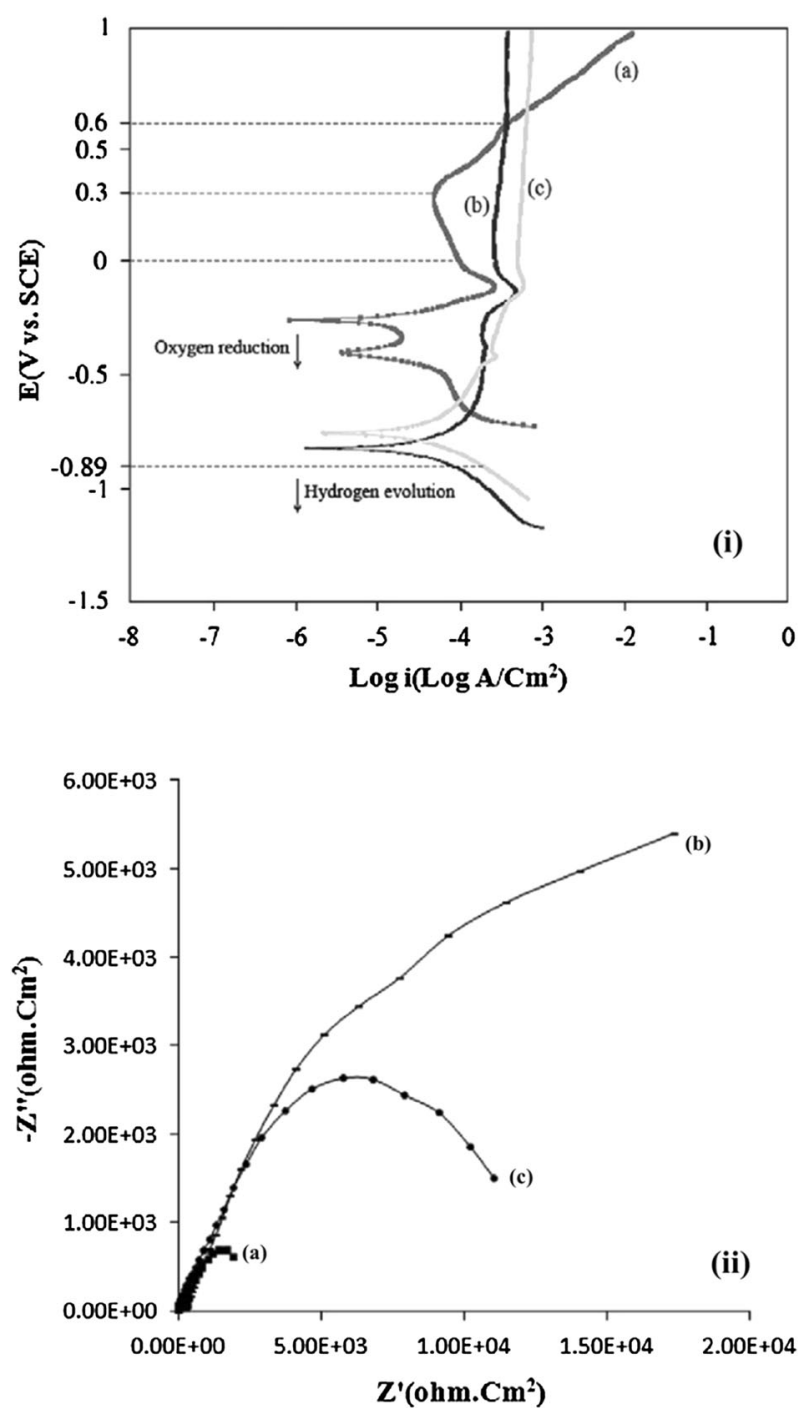

Fig. 12-(i) Potentiodynamic polarization and (ii) Nyquist plots for microcrystalline $\mathrm{Cu}$ sheet and nanocrystalline $\mathrm{Cu}$ coatings exposed to a $0.1 \mathrm{M} \mathrm{NaOH}$ solution: (a) $\mathrm{Cu}$ sheet, $(b) \mathrm{Cu}$ coating $40 \mathrm{~nm}$ grain size, and $(c) \mathrm{Cu}$ coating $90 \mathrm{~nm}$ grain size. ${ }^{[125]}$

sion has also been reported to decrease for $\mathrm{Cu}$-based nanocrystalline alloys as compared to the coarse-grained counterparts. $^{[110]}$

Youssef et al. ${ }^{[143]}$ have found that in de-aerated $0.5 \mathrm{~N}$ $\mathrm{NaOH}$ solution, both corrosion current density $\left(i_{\text {corr }}\right)$ and minimum passivation current density $\left(i_{\text {pass }}\right)$ of a nanocrystalline $\mathrm{Zn}$ prepared by electro-deposition (grain size $56 \mathrm{~nm}$ ) to be considerably smaller than those of the conventional electro-galvanized $\mathrm{Zn}$ (grain size 8 to $20 \mu \mathrm{m})$. On the basis of AC impedance measurements, the authors have suggested that the nature of protective film formed on the nanocrystalline electrodeposit was superior as compared to the polycrystalline film. The average capacitance of the nanocrystalline film was considerably lower $\left(69 \mu \mathrm{F} / \mathrm{cm}^{2}\right)$ as compared to that of the polycrystalline film $\left(227 \mu \mathrm{F} / \mathrm{cm}^{2}\right)$. Such improvements in corrosion behavior have also been evidenced in other alloy systems, viz., W-Ta alloy film produced by magnetron sputtering, ${ }^{[144]}$ nanocrystalline $\mathrm{Zr}$-based alloys (as compared to amorphous $\mathrm{Zr}$ alloys) ${ }^{[145]}$ and Co-based alloys. ${ }^{[107,117]}$

\section{Mechanistic Role of Nanocrystalline Structure in Aqueous Corrosion}

Despite considerable existing literature on aqueous corrosion of nanocrystalline materials, it is quite difficult to devise a simple mechanism of corrosion in such materials. This is primarily because of the wide variety of metals/alloys and the test media. It is important to emphasize that the grain size may not be the only governing criteria that can affect the corrosion of nanocrystalline metals/alloys. The synthesis techniques and the resulting defect structure and chemistry may have a profound effect on the corrosion behavior which essentially means that materials with same bulk chemistry can have different corrosion behaviors owing to non-chemical structural changes. Precisely for this reason, the reported studies point toward a generic/intuitive conclusion rather than a comprehensive corrosion mechanism. Salient features are summarized here.

- The majority of reports have concluded that the solubility of the corrosion product formed may determine the corrosion resistance of nanocrystalline materials. If the corrosion product is insoluble in the aqueous media then the nanocrystalline structure improves the corrosion resistance and vice versa. This postulate is based on the increased area fraction of chemical inhomogeneity on the fine-grained surface which can facilitate either the rapid formation of a passive layer or enhanced corrosion depending on the solubility of the corrosion product.

- A general consensus among such researchers is the elimination of localized attack at the nanocrystalline grain boundaries because of the solute dilution effect, the crystallographic texture changes due to grain refinement and the effect of grain size on the morphology of the passive film formed. ${ }^{[123]}$

- In contrast to above mechanistic inferences, a number of studies have advocated either an increased dissolution and corrosion rate or no significant difference upon reduction in grain size to nanocrystalline regime. These two effects have been explained on the basis of increased surface activity/energy in nanocrystalline materials and the artifacts such as porosity that are introduced during processing of nanocrystalline materials.

Though there may not be a common mechanism by which nanocrystalline structure influences aqueous corrosion, there are distinct instances where nanostructure has been found to considerably influence the electrochemical phenomenon and corrosion resistance.

\section{Shift in corrosion potential}

The corrosion potential $\left(E_{\text {corr }}\right)$ provides a qualitative guideline for susceptibility of the material to aqueous 
corrosion. The shift of $E_{\text {corr }}$ toward a more noble potential has been observed in various nanocrystalline metals/alloys like $\mathrm{Ni} .^{[10]}$ Rofagha et al. ${ }^{[10]}$ have attributed this behavior to the ability of nanocrystalline surface to enhance the catalysis of hydrogen evolution reaction, i.e. the reduction reaction which is known to be affected by defects and dislocation. ${ }^{[10,146]}$ In addition to this, the reversible trapping of hydrogen at the dislocations, grain boundaries, and voids (pores) can change the kinetics of hydrogen evolution. Therefore, higher content of such defects can shift the OCP value in the more noble direction. ${ }^{[10,146,147]}$ This observation is duly complemented by other reports on $\mathrm{Fe}-\mathrm{Cr}$ alloys in sulfate solution ${ }^{[129,130]}$ where nanocrystalline structure did not change the corrosion potential. The primary cathodic reaction in the $\mathrm{Fe}-\mathrm{Cr}$-sulfate system is the oxygen reduction reaction (rather than the hydrogen evolution) where catalysis does not play a significant role.

\section{Electrochemical characteristic of grain boundaries}

Grain boundaries are almost always anodic to the grain matrix. The finer the grain size, the greater will be the grain boundary area, which will improve the resistance of nanocrystalline structure to localized electrochemical dissolution by two phenomena:

(a) In galvanic corrosion of two dissimilar metals, having a lower anode-cathode area ratio is undesirable. A smaller anodic surface area leads to a more intense and localized attack. ${ }^{[148]}$ Similarly, in case of nanocrystalline materials, the larger anodic area (due to high grain boundary area fraction) leads to increase in the anode-cathode area ratio as compared to microcrystalline alloys, which results in dissipation of localized attack by aggressive ions.

(b) Certain impurities enhance the anodic behavior of grain boundaries. A large cumulative grain boundary area (such as in nanocrystalline structures) will decrease the impurity content per unit area which leads to a decrease in the electrochemical potential-difference between grains and grain boundaries, thus, improving corrosion resistance. This effect is known as the solute-dilution effect. ${ }^{[149]}$ Indeed, a number of nanocrystalline metals/alloys have been shown to exhibit improved resistance to pitting and localized corrosion. ${ }^{10,107,116,126,133,146]}$

Another factor contributing to the improved corrosion resistance of nanocrystalline structures is the greater number of nucleation sites for the passive-layer which leads to a rapid establishment of a homogeneous passive film. On the other hand, the microcrystalline alloy undergoes localized corrosion and forms an inhomogeneous passivating layer. This is consistent with the observations by Ye et al. ${ }^{[133]}$ where though the difference between the corrosion current density of nanocrystalline and microcrystalline stainless steels was insignificant, the passive region is much extended in nanocrystalline steel. Also, the breakdown potential was much higher for the nanocrystalline alloy along with no evidence of pitting/metastable pitting. The phenomena conform to the pit-initiation and fast metastable pitting mechanism in nanocrystalline austenitic stainless steel (SS) proposed by Liu et al. ${ }^{[150]}$ Such considerable improvement in localized corrosion behavior of nanocrystalline alloys has also been reported in AZ91D Mgalloy, ${ }^{[151]} \mathrm{Fe}-20 \mathrm{Cr}$ alloy, ${ }^{[124,152]} 309$ stainless steel $^{[153]}$ and pure A1. ${ }^{[154]}$

A contrasting observation to the beneficial effects of nanocrystalline structure has been reported in the case of Cu90-Ni10 alloy. ${ }^{[122]}$ The corrosion resistance and breakdown potential of the nc alloy were shown to be inferior to the microcrystalline alloy of the same composition. Interestingly, the authors have attributed the phenomena to a combination of two factors, namely, the reduced compactness of an oxide film due to irregular growth at grain boundaries and secondly, the defects incorporated during the processing of the nc alloy. However, they have not provided the difference in the porosity of the nanocrystalline and microcrystalline samples.

\section{Effect of greater grain boundary diffusion}

Several reports have discussed the possibility of enhanced grain boundary diffusion affecting the corrosion behavior of nanocrystalline alloys. ${ }^{[133,155,156]}$ These studies on 309 and 316 stainless steels have argued that the improvement in general and localized corrosion of nanocrystalline alloys is due to increased diffusion of $\mathrm{Cr}$ in the alloy matrix that facilitates the establishment of a passive layer. It has also been conclusively shown by XPS and SIMS analyses in other reports that indeed the $\mathrm{Cr}$ content in the passive layer is significantly higher than the bulk Cr-concentration of the $\mathrm{Fe}-\mathrm{Cr}$ alloys. ${ }^{[124,129]}$ However, the argument supporting the enhanced Cr-diffusion at room temperatures is quite questionable. Using the data extrapolated from higher temperatures for grain boundary and lattice diffusion coefficients, the effective diffusion rates at nanocrystalline and microcrystalline grain sizes can be calculated at room temperature. For a grain size of $10 \mathrm{~nm}$, this value is estimated to be $1.2 \times 10^{-40}$ as compared to a value of $8 \times 10^{-43}$ for a grain size of $5 \mu \mathrm{m} .{ }^{[129]}$ Although there seems to be three orders of magnitude difference in the diffusion rates, at such low diffusion coefficients, it is hard to conceive any active role of diffusion in the formation of $\mathrm{Cr}$-rich passive layer.

\section{Selective dissolution}

In the absence of any formidable evidence in support of other theories, the most plausible explanation for the greater $\mathrm{Cr}$-content of the passive layer formed in nanocrystalline $\mathrm{Fe}-\mathrm{Cr}$ alloys has been proposed as the selective dissolution of Fe. ${ }^{[129]}$ Selective dissolution occurs in a potential regime when one of the alloying elements forms a stable corrosion product whereas the other alloying element dissolves. This mechanism has been quite well established for many alloy systems in the conventional grain size regime, viz., stainless stee ${ }^{[157-159]}$ and $\mathrm{Zn}-\mathrm{Al} .^{[160,161]}$ For a binary alloy A-B, selective dissolution can be quantitatively described by evaluating the coefficient of selective dissolution: 


$$
Z_{\mathrm{A}}=\frac{\left(C_{\mathrm{A}} / C_{\mathrm{B}}\right)_{\text {solution }}}{\left(C_{\mathrm{A}} / C_{\mathrm{B}}\right)_{\text {alloy }}},
$$

where $C_{\mathrm{A}}$ and $C_{\mathrm{B}}$ are the concentrations of $\mathrm{A}$ and $\mathrm{B}$, respectively. This mechanism could be of particular importance in nanocrystalline materials because the reduction in grain size will increase the surface reactivity which in-turn will increase both the contributing processes - (a) formation of a passive film rich in alloying element A, and (b) the dissolution of element B. Hence, the effect of selective dissolution is more pronounced in nanocrystalline materials. This has been observed in several nanocrystalline alloying systems, namely, $\mathrm{Fe}-\mathrm{Cr},{ }^{[124,129]} \mathrm{Co}-\mathrm{P},{ }^{[107,162]}$ and $\mathrm{Zr}-\mathrm{Ni}{ }^{[163]}$

\section{Empirical relationship between corrosion rate and grain-size}

In a recent work, Ralston et al.,${ }^{[6]}$ have shown that an empirical relationship (which is analogous to Hall-Petch relation for yielding behavior of material) can be observed between corrosion current density and grain size. This is the first investigation to report a quantitative expression explaining the effect of grain size. The corrosion current density is related to grain size as ${ }^{[6]}$ :

$$
i_{\text {corr }}=(A)+(B) g s^{-0.5},
$$

where $A$ depends on the electrolytic/corrosive media and $B$ represents a material constant which differs according to the composition and impurity level of the alloy. Such dependence is seen in $\mathrm{Ni}-\mathrm{Al},{ }^{[150]} \mathrm{Ni}-\mathrm{Cu},{ }^{[118]} \mathrm{Al},{ }^{[6]}$ and $\mathrm{Mg} \cdot{ }^{[164,165]}$ The justification of is based on the increase in the ionic conduction of the passive layer due to the decrease in grain size, which significantly alters the role of anodic reaction and hence the corrosion current density. This effect was only observed for alloy-electrolyte systems which show passivation. It is not specified by the authors why such a phenomena is not observed in "active" alloy electrolyte systems. However, it seems plausible that in the absence of a passive film (and the increased ion conduction associated with the refined grains), the only factor governing the corrosion rate is the higher thermodynamic energy associated with the finer grain size leading to increased dissolution rates. It would be interesting to investigate if an "inverse" trend is observed for systems which do not show any passivation.

A very important aspect of corrosion of nanocrystalline materials which has not received sufficient research attention is the time-dependent investigation of evolution of passive film in nc materials which is essential to validate the mechanism of passive film formation (e.g., diffusion-assisted mechanism, selective dissolution, etc.). Another focus area could be the comparison of corrosion resistance exhibited by nanocrystalline alloys having same composition and grain size but produced by different synthesis routes like USSP, SMAT, powder compaction, ECAP/ECAE, PED, CVD, and even sputter-deposited coatings. This aspect is important in order to eliminate the effect of characteristic features introduced by different synthesis routes like porosity, impurity concentration, defect density, etc.

This section has highlighted the electrochemical corrosion behavior of nanocrystalline alloys. The current state may not allow to present a single and consensus mechanism for the role of nanocrystalline structure on aqueous corrosion. However, a comprehensive description of the behavior of nanocrystalline metals/alloys has been presented in a range of electrochemical conditions.

\section{HIGH TEMPERATURE OXIDATION}

\section{A. General Principles}

During oxidation, binary alloys with certain alloying elements (viz., $\mathrm{Cr}, \mathrm{Al}$, and $\mathrm{Si}$ ) can form a continuous layer of the chromia, alumina, or silica, conferring substantial oxidation resistance. This principle has formed the basis of the development of common alloys for oxidation resistance, such as stainless steels. Formation of a continuous layer of surface oxide is called external oxidation. ${ }^{[166]}$ If, on the other hand, the inward flux of oxygen exceeds the outward flux of solute during oxidation process, isolated oxide particles form in the sub-surface. This phenomenon is called internal oxidation. ${ }^{[166]}$ The critical solute concentration, $N_{\mathrm{C}}$ for the transition from internal to external oxidation of an alloy can be calculated by Wagner's treatment ${ }^{[167]}$ and is expressed as:

$$
N_{\mathrm{c}}=\left(\frac{\pi g^{*} N_{\mathrm{o}} D_{\mathrm{o}} V_{\mathrm{M}}}{3 D_{\mathrm{s}} V_{\mathrm{Ox}}}\right)^{1 / 2}
$$

where $N_{\mathrm{o}} D_{\mathrm{o}}$ is oxygen permeability in the alloy, $D_{\mathrm{s}}$ is the diffusivity of the solute atom, $g^{*}$ is a factor determined by the volume fraction of oxide required for the transition, and $V_{\mathrm{M}}$ and $V_{\mathrm{Ox}}$ are the molar volumes of the alloy and oxide, respectively. The concentration of the solute that forms the protective oxide layer should be greater than $N_{\mathrm{c}}$ in order to form a continuous $\mathrm{M}_{x} \mathrm{O}_{\mathrm{y}}$ external scale. The reduction in grain size to nanocrystalline regime serves a two-fold purpose. First, it significantly increases the high energy sites (grain boundaries and triple junctions) on the surface of the alloy for oxide nucleation. More importantly, the extremely fine grain size and the high volume fraction of grain boundaries of nanocrystalline (nc) alloys ${ }^{[12]} \mathrm{can}$ cause an extraordinary increase in diffusion kinetics, and therefore, the nanocrystalline structures may have beneficial effects in the development of the protective oxide layer. For example, oxidation resistance of $\mathrm{Fe}-\mathrm{Al}$ and $\mathrm{Fe}-\mathrm{B}-\mathrm{Si}$ alloys in the nanocrystalline state is reported $^{[131,168]}$ to be superior to their oxidation resistance in microcrystalline state. This behavior is attributed to $\mathrm{Al}$ and $\mathrm{Si}$, the well-known protective oxide film formers, being the predominantly diffusing species, respectively, in the two alloys, and the nanostructure facilitating their diffusion and expedited formation of protective films (of $\mathrm{Al} / \mathrm{Si}$ oxide). 


\section{B. Alumina Forming Nanocrystalline Alloys/Coatings}

Traditional high temperature oxidation resistant coatings can be classified into three types: the coatings which form aluminides or modified aluminides such as $\mathrm{Cr}-\mathrm{Al}$, Si-Al, and Pt-Al ${ }^{[169-173]}$; the overlayer coatings which are of the form MCrAlY (M-can be Fe, Co, and/or $\mathrm{Ni})^{[174-177]}$ and the thermal barrier coatings which are of the form MCrAlY $+\mathrm{Y}_{2} \mathrm{O}_{3} / \mathrm{ZrO}_{2} /$ $\mathrm{CeO}_{2} \cdot{ }^{[178-181]}$ However, as a result of interdiffusion or thermal mismatch between the coating and the substrate, the mechanical properties of such coatings are quite unsatisfactory. ${ }^{[181]}$ Recent studies have shown that high temperature oxidation resistant coatings can be developed by the surface modification to a nanocrystalline domain. The selective oxidation of the coated nanocrystalline layer to form an oxide phase which imparts the maximum oxidation resistance has been successfully exploited by various researchers to design oxidation resistant coatings. The nanocrystalline coatings of superalloys developed by magnetron sputtering have been found to possess excellent oxidation resistance in comparison to the microcrystalline alloys of the same composition. For example, K38G (4 pctAl and 16 pct $\mathrm{Cr}){ }^{[182,183]} \mathrm{KF} 17$ (4 pctAl and $\left.12.5 \mathrm{pctCr}\right){ }^{[184]}$ and LDZ125 (5.2 pctAl and 9.5 pctCr $)^{[185,186]}$ form a predominantly single phase $\mathrm{Al}_{2} \mathrm{O}_{3}$ scale, whereas, the microcrystalline counterparts of these coatings form a mixture of $\mathrm{Cr}_{2} \mathrm{O}_{3}$ and $\mathrm{Al}_{2} \mathrm{O}_{3}$. The cross-sectional micrograph of the oxide films formed on a nanocrystalline and as-cast K38G superalloy have confirmed the selective oxidation of $\mathrm{Al}$ in the case of nanocrystalline alloy, resulting in a unitary layer of $\mathrm{Al}_{2} \mathrm{O}_{3}{ }^{[187]}$ Superior oxidation resistance due to the nanocrystalline structure of coatings has been reported also by Liu et al. ${ }^{[101,188,189]}$ in the case of a Ni-20Cr-2Al superalloy. The coating with grain size of $65 \mathrm{~nm}$ showed a considerable improvement in oxidation resistance over the coating with an average grain size in the range of 280 to $350 \mathrm{~nm}$ (the latter showed a resistance similar to the uncoated bare alloy). A mechanism of selective oxidation of $\mathrm{Al}$, to develop a full-fledged $\mathrm{Al}_{2} \mathrm{O}_{3}$ layer, despite the significantly low $\mathrm{Al}$ content is proposed on the basis of the nanometric grain size facilitating the "third-element effect". ${ }^{[190,191]}$ During the initial stages of oxidation of $\mathrm{Ni}-\mathrm{Al}-\mathrm{Cr}$ alloys, oxides of $\mathrm{Ni}, \mathrm{Cr}$, and $\mathrm{Al}$ are formed, largely in the ratio of their bulk concentrations. However, subsequently, because of the enhanced diffusion of $\mathrm{Cr}$ and $\mathrm{Al}$ in the nanocrystalline alloy matrix, the establishment of full-fledged layers of $\mathrm{Cr}_{2} \mathrm{O}_{3}$ and $\mathrm{Al}_{2} \mathrm{O}_{3}$ is much more rapid in case of nanocrystalline alloys as compared to the coarser grained alloys. If the $\mathrm{Cr}$ content is high enough, as in the case of Ni-20Cr-2Al alloy, a continuous layer of $\mathrm{Cr}_{2} \mathrm{O}_{3}$ would be expected to form on the surface. The formation of a $\mathrm{Cr}_{2} \mathrm{O}_{3}$ layer alters the defect structure in the oxide layer and affects the diffusion/ion exchange through the oxide layer. As a result, the oxygen partial pressure at the oxide-alloy interface is affected such that it becomes equal to the equilibrium partial pressure required for the exclusive formation of $\mathrm{Al}_{2} \mathrm{O}_{3}$ that grows into a continuous layer. In the above mechanism, the role of nanocrystalline alloy structure in the initial establishment of the $\mathrm{Cr}_{2} \mathrm{O}_{3}$ layer, and therefore the $\mathrm{Cr}$ concentration is critically important for forming a continuous layer of alumina. Subsequent studies on various other compositions of NiAl-Cr ternary system have supported this mechanism. ${ }^{[191-195]}$ An oxide map (Figure 13), which enables the prediction of oxide phases present in the scale after oxidation at $1273 \mathrm{~K}\left(1000{ }^{\circ} \mathrm{C}\right)$, for $\mathrm{Ni}-\mathrm{Cr}$-Al ternary alloys has been generated by Chen and Lou. ${ }^{[191]}$ Figure 13 shows the oxide phases formed for different compositions of $\mathrm{Ni}-\mathrm{Al}-\mathrm{Cr}$ ternary when the grain sizes are in nanocrystalline and microcrystalline regimes. A comparison between the oxide maps for nanocrystalline and microcrystalline $\mathrm{Ni}-\mathrm{Cr}-\mathrm{Al}$ alloys suggests that the boundaries between different oxide-forming zones for $\mathrm{Ni}-\mathrm{Cr}-\mathrm{Al}$ nanograined alloys move toward the Ni-rich corner.

Nanocrystalline structure can not only promote the transition from internal to external oxidation at lower alloying additions but can also enhance the adherence of the oxide film on the surface of the substrate. Contrary to the above examples where $\alpha-\mathrm{Al}_{2} \mathrm{O}_{3}$ developed exclusively when nanocrystalline alloy structure was available, certain alloys (viz. Co-30Cr-5Al and $\mathrm{Ni}_{3}(\mathrm{AlCr})$ ) form a continuous alumina scale even when the alloy grain size is in microcrystalline regime. However, the nanocrystalline structure showed a considerably superior resistance to oxide scale spallation. The fine grained oxide layer is more capable of accommodating the growth stresses during isothermal oxidation (by grain boundary sliding) as well as the thermal stresses during cooling (by plastic deformation). ${ }^{[181]}$ Furthermore, anchoring of the oxide scale via "micro-pegs" (Figure 14) is more effective due to greater grain boundary area in the nanocrystalline alloy. ${ }^{[181]}$

\section{Chromia Forming Nanocrystalline Alloys}

There are relatively fewer studies addressing the effect of nanocrystalline grain size on the oxidation of chromia forming alloys. This section reviews the oxidation resistance, oxide scale morphology, and mechanism of oxidation of chromia forming nanocrystalline vis-á-vis microcrystalline alloys of similar compositions.

Zhang et al. ${ }^{[196]}$ compared the oxidation resistance of a nanocrystalline Ni-9.6Cr (grain size $39 \mathrm{~nm}$, prepared by electrodeposition), an electrodeposited pure $\mathrm{Ni}$ (grain size $31 \mathrm{~nm}$ ) and uncoated microcrystalline Ni. The weight gain after 24 hours of oxidation at $1073 \mathrm{~K}$ $\left(800^{\circ} \mathrm{C}\right)$ was much smaller for the $\mathrm{Ni}-\mathrm{Cr}$ nanocrystalline alloy $\left(0.43 \mathrm{mg} / \mathrm{cm}^{2}\right)$ as compared to the electrodeposited Ni film $\left(1.8 \mathrm{mg} / \mathrm{cm}^{2}\right)$ and the microcrystalline Ni matrix $\left(1.4 \mathrm{mg} / \mathrm{cm}^{2}\right)$. Figure 15 illustrates their oxide morphology and weight gain data. The study was able to establish that the Ni-Cr nanocrystalline alloy possessed the ability to form a contiguous layer of chromia even at low $\mathrm{Cr}$ concentrations, thus improving its oxidation resistance.

Song et al. ${ }^{[197]}$ and Niu et al.$^{[198]}$ have shown that the oxidation behavior of nanocrystalline and microcrystalline binary $\mathrm{Ag}-\mathrm{Cr}$ alloys to be remarkably different. $\mathrm{Ag}$ and $\mathrm{Cr}$ are entirely immiscible in each other, and both 


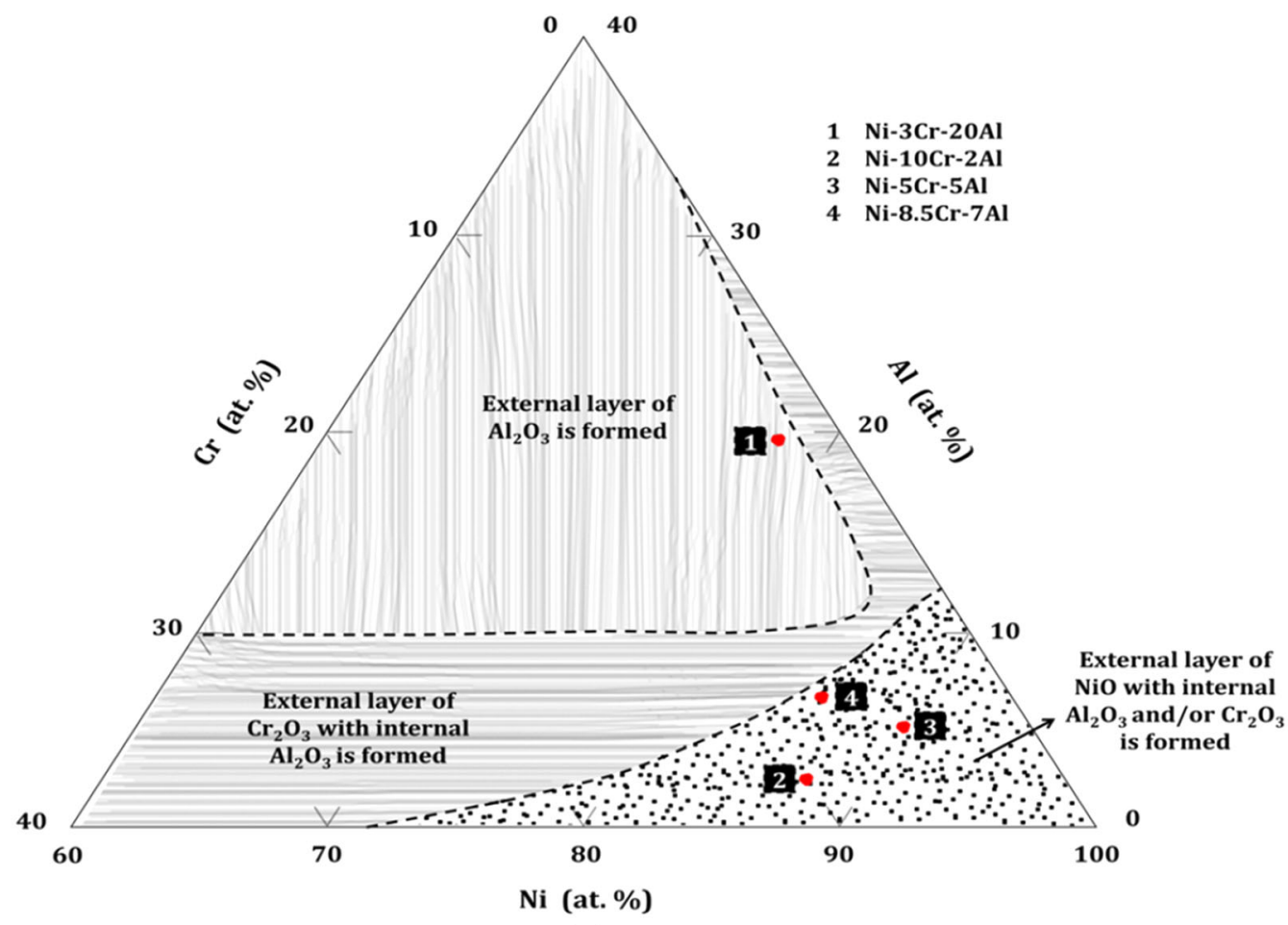

(a)

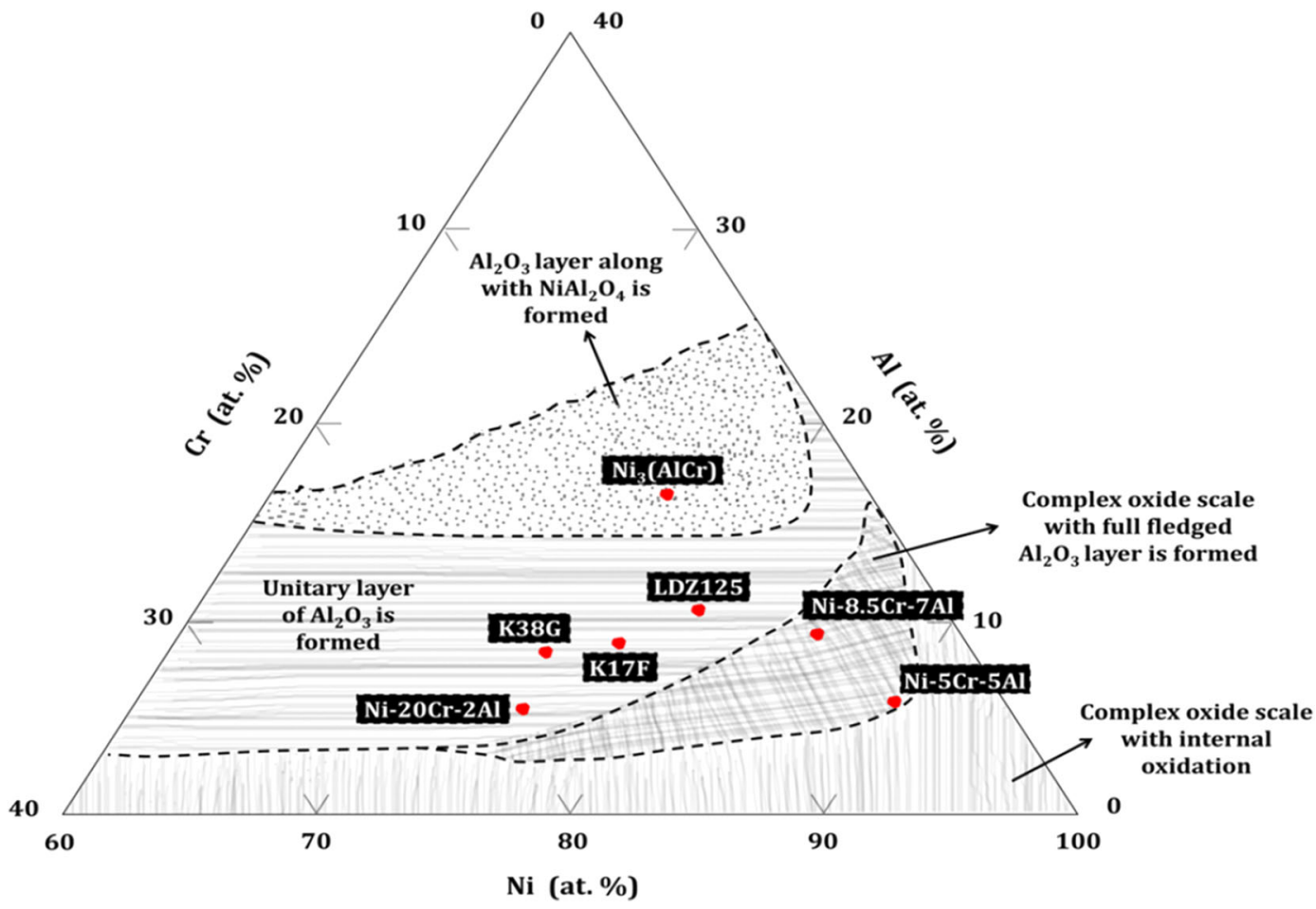

(b)

Fig. 13 - Oxide maps for ternary Ni-Al-Cr alloys at $1273 \mathrm{~K}\left(1000{ }^{\circ} \mathrm{C}\right)(a)$ microcrystalline alloys, and $(b)$ nanocrystalline coatings. Boundaries for different oxide forming zones are shifted toward the Ni-rich corner. Image modified and redrawn from Chen and Lou. ${ }^{[191]}$

the nano- and microcrystalline alloys, produced by a powder metallurgical route, contained a uniform dispersion of Ag-rich $\alpha$ and Cr-rich $\beta$-phases, but at nanoand microscales, respectively. During oxidation at
$973 \mathrm{~K}$ to $1073 \mathrm{~K}\left(700{ }^{\circ} \mathrm{C}\right.$ to $\left.800{ }^{\circ} \mathrm{C}\right)$, the nanocrystalline alloys form an outer layer of double $\mathrm{Ag}-\mathrm{Cr}$ oxide $\left(\mathrm{AgCrO}_{2}\right)$ with a layer of chromia underneath (which suppresses the internal oxidation of $\mathrm{Cr}$ ) and a 

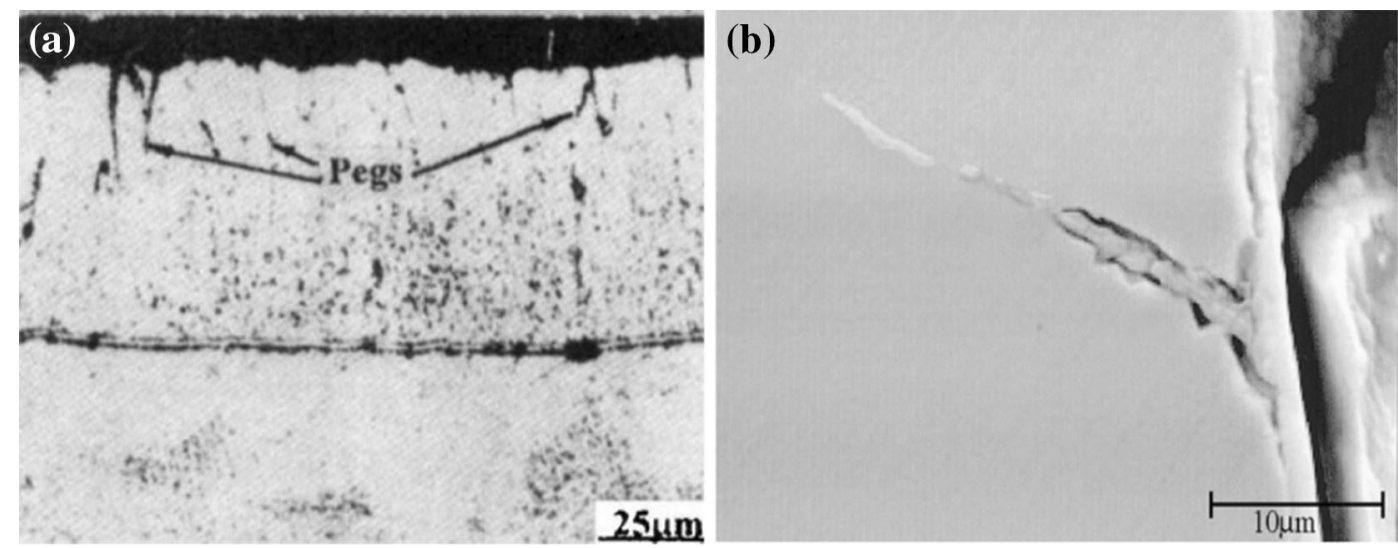

Fig. 14 Cross-sections of $(a) \mathrm{Ni}_{3}(\mathrm{AlCr})$ nanocrystalline coating after oxidation at $1173 \mathrm{~K}\left(900{ }^{\circ} \mathrm{C}\right)$ for 200 -h ${ }^{[181]}$ and $(b)$ microcrystalline Fe ${ }_{3} \mathrm{Al}-\mathrm{Y}$ alloy after oxidation at $1373 \mathrm{~K}\left(1100{ }^{\circ} \mathrm{C}\right)$ for $120-\mathrm{h},{ }^{[213]}$ showing the formation of micro-pegs.
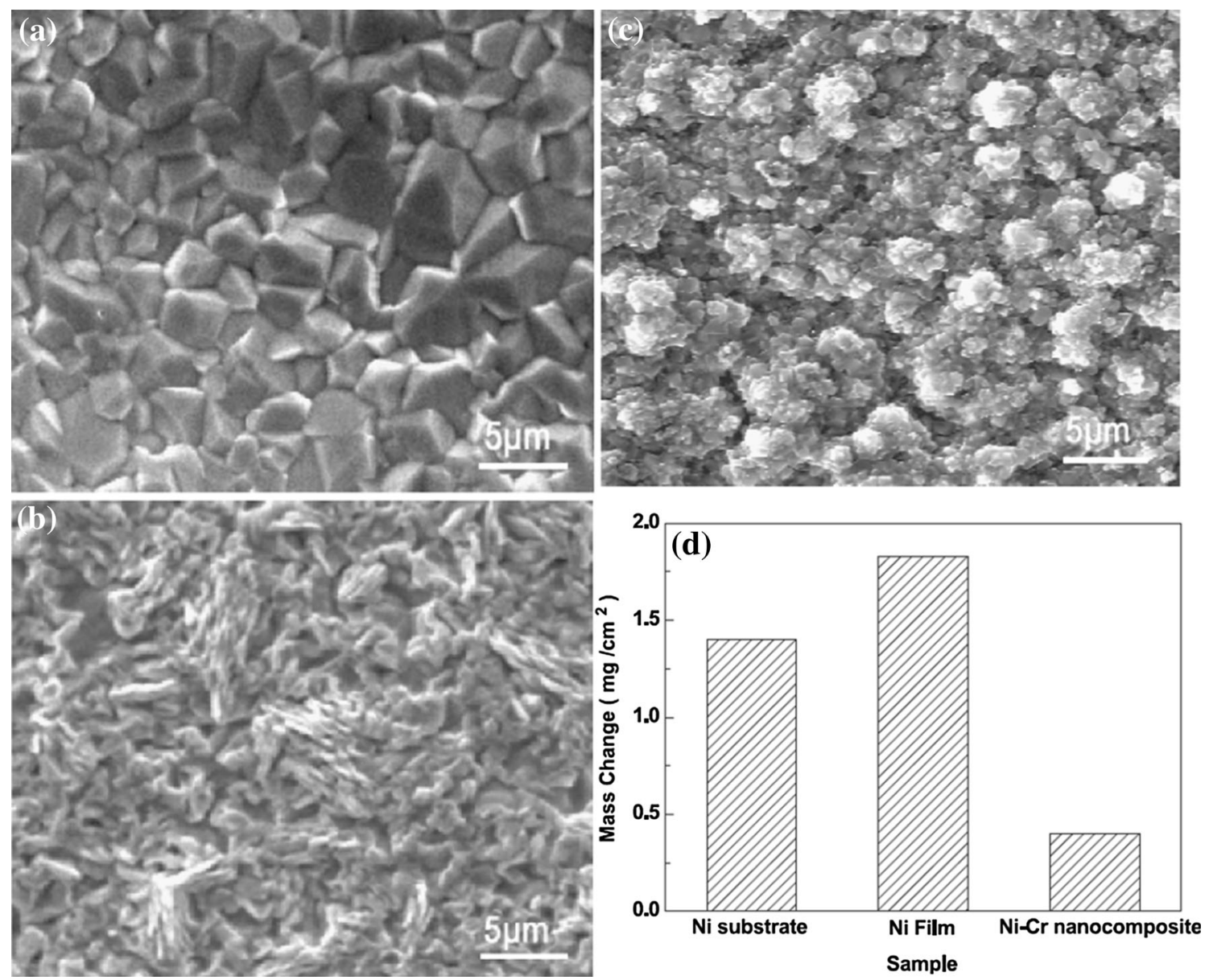

Fig. 15-Surface morphologies of the oxide scales formed on (a) uncoated $\mathrm{Ni}$, $(b)$ electrodeposited Ni Film and $(c)$ Ni-9.6Cr nanocomposite, and (d) Mass change for various samples after 24 -h oxidation at $1073 \mathrm{~K}\left(800^{\circ} \mathrm{C}\right) .{ }^{1196]}$

Cr-depleted $\alpha$-phase in the sub-scale beneath the chromia layer. The authors have attributed this behavior to the large concentration of grain boundaries, which act as preferential diffusion paths for chromium in the alloy, thereby facilitating sufficient $\mathrm{Cr}$ enrichment and development of a full-fledged chromia layer that slows down the oxidation rate quite significantly. Moreover, the relatively fast dissolution of the nano-sized $\beta$-phase particles in the $\mathrm{Cr}$-depleted $\alpha$-matrix provides an effective chromium reservoir for sustaining the $\mathrm{Cr}_{2} \mathrm{O}_{3}$ layer. In contrast, the microcrystalline variants of these alloys were incapable of forming full-fledged $\mathrm{Cr}_{2} \mathrm{O}_{3}$ layer at the test temperatures. At 17 and 35 pct $\mathrm{Cr}$ in the microcrystalline alloys, the oxide scales contained a sub-scale 

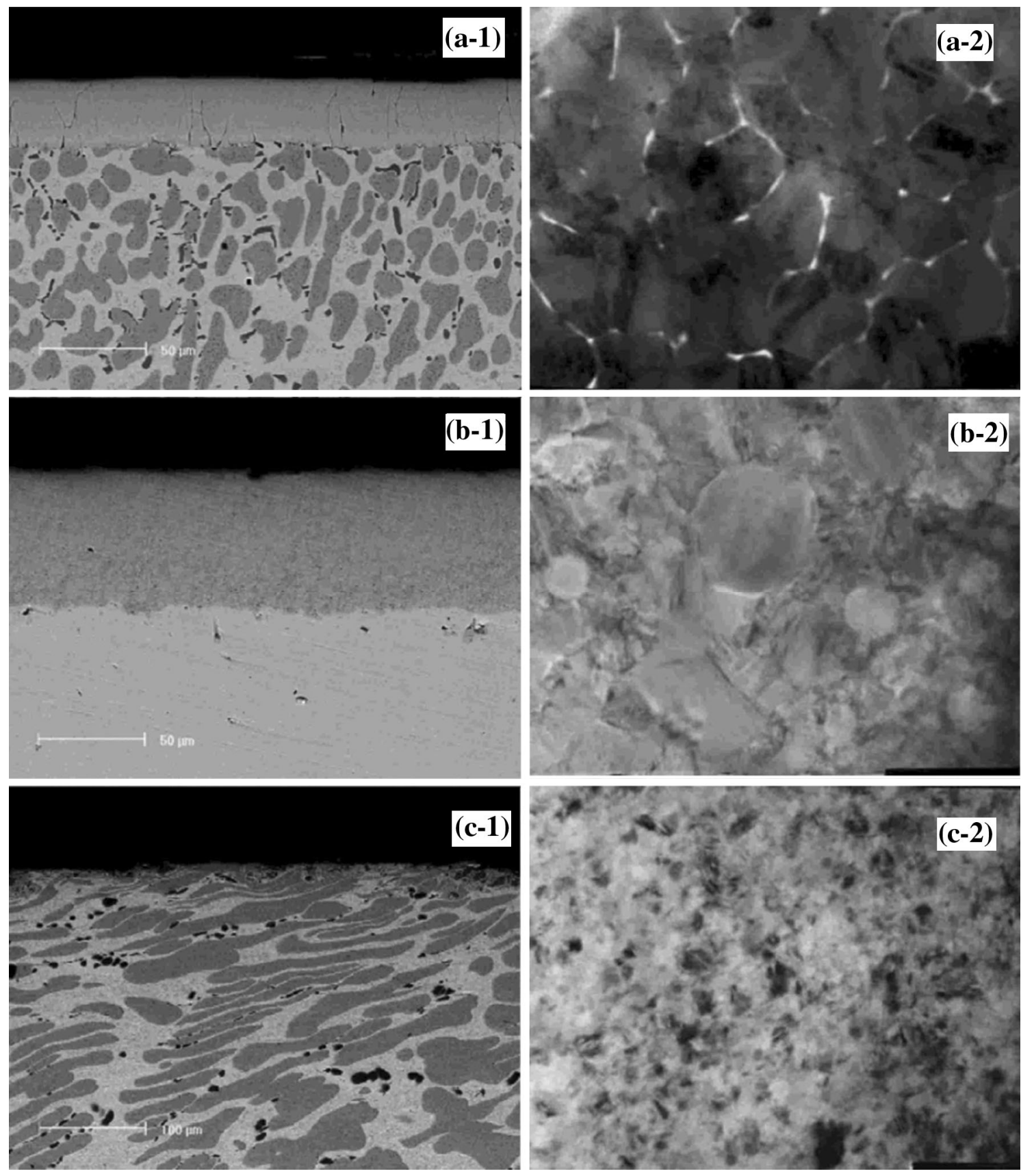

Fig. 16 ( $a$-1 through $c-1)$ Cross-sectional SEM and ( $a$-2 through $c$-2) corresponding TEM images of Cu-30Ni-20Cr nanocrystalline alloys fabricated using DCMS $(a-1,2)$, NCE $(b-1,2)$, and $\operatorname{SMAT}(c-1,2)$, respectively. ${ }^{[199]}$

of internal oxide of $\mathrm{Cr}$ underneath the external layer of either $\mathrm{AgCrO}_{2}$ or a mixture $\mathrm{AgCrO}_{2}$ and $\mathrm{Cr}_{2} \mathrm{O}_{3}$. At 69 pct $\mathrm{Cr}$ in the microcrystalline alloy, although the internal oxidation is significantly suppressed, the oxide scale still contained only a mixture of $\mathrm{Cr}_{2} \mathrm{O}_{3}$ and $\mathrm{AgCrO}_{2}$ but no exclusive layer of $\mathrm{Cr}_{2} \mathrm{O}_{3}$.

Huang et al. ${ }^{[199]}$ studied the effect of nanocrystalline structure and the spatial $\mathrm{Cr}$ distribution on the development of a chromia scale. The study compared three compositionally same $\mathrm{Cu}-30 \mathrm{Ni}-20 \mathrm{Cr}$ alloys fabricated using different synthesis routes, namely, DCMS, nanocomposite electrodeposition (NCE) and SMAT. The purpose of employing three different processing routes was to prepare alloys with different spatial Cr-distributions (Figure 16), i.e., atomic length scale distribution (in DCMS), nano-length scale distribution (in NCE) and micrometer length scale distribution (in SMAT). The high temperature oxidation behavior (at $1073 \mathrm{~K}$ $\left(800{ }^{\circ} \mathrm{C}\right)$ ) of the three nanocrystalline and a coarsegrained (CG) alloy of same composition was quite different (Figure 17). The calculated rate constant for oxidation of CG alloy was in excess of two orders of magnitude greater than the reported rate constant for pure $\mathrm{Cr}$, suggesting the inability of the $\mathrm{CG}$ alloy to form 


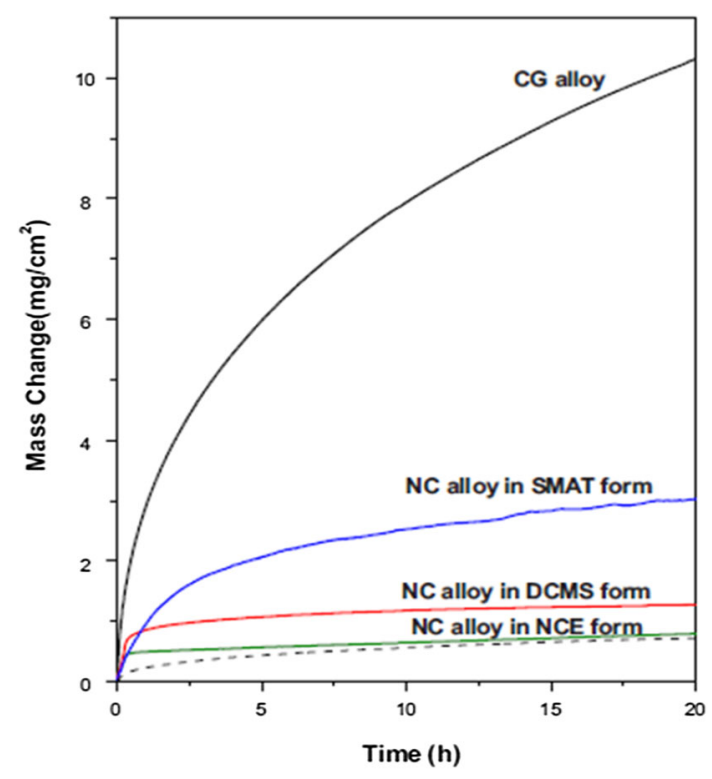

Fig. 17- Oxidation kinetics curves of various $\mathrm{Cu}-30 \mathrm{Ni}-20 \mathrm{Cr}$ samples at $1073 \mathrm{~K}\left(800^{\circ} \mathrm{C}\right)$ in air for $20 \mathrm{~h}$. The dashed line shows the oxidation curve of a pure $\mathrm{Cr}$ for comparison. ${ }^{[196]}$

a protective oxide film of $\mathrm{Cr}_{2} \mathrm{O}_{3}$. The parabolic rate constants in case of DCMS and NCE alloys were very close to that of pure $\mathrm{Cr}$ which indicates that these alloys formed a $\mathrm{Cr}_{2} \mathrm{O}_{3}$ layer. However, the parabolic rate constant for the SMAT alloy was an order of magnitude higher than that for pure Cr. Establishment of a fullfledged $\mathrm{Cr}_{2} \mathrm{O}_{3}$ layer also marked the transition to a steady-state oxidation stage after an initial transient stage (which was 20 minutes for the DCMS alloy, 30 minutes for the NCE alloy and 2.5 hours for the SMAT alloy). As characterized using XRD and EDX, the three nc alloys (DCMS, NCE, and SMAT) confirmed the formation of chromia, whereas the oxide scale on the CG alloy was mainly composed of mixed oxides of $\mathrm{CuO}, \mathrm{Cu}_{2} \mathrm{O}$, and $\mathrm{NiO}$. The surface and crosssectional micrographs of the oxide layers of the three nc alloys are shown in Figure 18. The inner layer of Cr-rich oxide starts to develop along the Cr-rich $\gamma_{2}$ phase in the nc alloys. The development of this layer considerably retards the otherwise rapid inward oxidation. DCMS alloy developed a fine structure of $\mathrm{Cr}_{2} \mathrm{O}_{3}$ with traces of a few large crystals of $\mathrm{CuO}$. The NCE alloy grew a finegrained chromia layer and a corresponding 3 to $5 \mu \mathrm{m}$ thick Cr-depleted zone. The SMAT nc alloy developed a chromia layer with isolated areas of $\mathrm{CuO}$ and iron oxides (the latter may be attributed to the contamination from balls employed in the SMAT process). The exclusive finding of this study is the conclusion that along with the nanocrystalline grain size, the spatial distribution of $\mathrm{Cr}$ also plays an important role in the development of protective $\mathrm{Cr}_{2} \mathrm{O}_{3}$ layer.

Cr-based alloys and high-Cr ferritic steels are used extensively as metallic interconnect materials in solidoxide fuel cells (SOFC). The specific requirements for metallic interconnects include high oxidation resistance and high electrical conductivity of the surface oxide layer (besides, gas tightness, and a specific coefficient of thermal expansion). Sebayang et al. ${ }^{[200]}$ have studied the effect of nanocrystalline grain size on various properties of ferritic $\mathrm{Fe}-20 \mathrm{Cr}$ alloy for SOFC application. The oxidation resistances of the nanocrystalline $\mathrm{Fe}-20 \mathrm{Cr}$ alloys (grain sizes 38 and $53 \mathrm{~nm}$ ) prepared by mechanical alloying and hot pressing were compared with commercially available ferritic $\mathrm{Fe}-\mathrm{Cr}$ steel, in the temperature range of $1173 \mathrm{~K}$ to $1373 \mathrm{~K}\left(900{ }^{\circ} \mathrm{C}\right.$ to $1100{ }^{\circ} \mathrm{C}$ ). The parabolic rate constant was found to be the smallest for the alloy having the minimum grain size. The surface oxide scales developed on the nc alloys were composed primarily of $\mathrm{Cr}_{2} \mathrm{O}_{3}$ whereas the oxide layer of the coarse-grained ferritic steel was composed primarily of $\mathrm{FeO}$. The authors have concluded that in case of nc $\mathrm{Fe}-20 \mathrm{Cr}$ alloys the oxidation is governed by the development of a full-fledged chromia layer, whereas the coarse-grained ferritic steel only develops a discontinuous $\mathrm{Cr}_{2} \mathrm{O}_{3}$ scale that allowed internal oxidation.

In the temperature regime of $573 \mathrm{~K}$ to $673 \mathrm{~K}\left(300{ }^{\circ} \mathrm{C}\right.$ to $400{ }^{\circ} \mathrm{C}$ ), chromium diffusion in a nanocrystalline $\mathrm{Fe}$ $\mathrm{Cr}$ system is reported to be about four orders of magnitude greater than in a microcrystalline $\mathrm{Fe}-\mathrm{Cr}$ alloy. ${ }^{[201]}$ Given the extremely fine grain size, and the resultant faster diffusion in nanocrystalline $\mathrm{Fe}-\mathrm{Cr}$ alloys, one would expect the $\mathrm{Cr}$ concentration required for internal-to-external oxidation transition to become substantially lower. Based on this principle, Singh Raman et al. ${ }^{[8]}$ hypothesized that the oxidation resistance of a nanocrystalline $\mathrm{Fe}-\mathrm{Cr}$ alloys should be considerably superior to microcrystalline alloys of same composition, and consequently, it should also be possible to attain remarkable oxidation resistance at considerably lower chromium contents in nanocrystalline $\mathrm{Fe}-\mathrm{Cr}$ alloys, as opposed to the minimum 13-15 wt pct required for development and maintenance of the $\mathrm{Cr}_{2} \mathrm{O}_{3}$ layers in common stainless steels. In this context, it should be mentioned that though the minimum chromium content for the development of $\mathrm{Cr}_{2} \mathrm{O}_{3}$ layer is 13 pct for ferritic alloys, and approx. 15 pet for austenitic alloys, common stainless steels contain at least $18 \mathrm{wt}$ pct chromium, in order to provide sufficient chromium in the subscale for the purpose of self-healing in the event of disruption in the initial protective layer of $\mathrm{Cr}_{2} \mathrm{O}_{3}$. A common high-Cr alloy (such as $18 \mathrm{Cr}-8 \mathrm{Ni}$ stainless steel) forms an inner layer of $\mathrm{Fe} / \mathrm{Ni}$ oxide, during initial stages of oxidation, which eventually converts into a protective oxide, i.e., $\mathrm{Cr}_{2} \mathrm{O}_{3}$ when sufficient $\mathrm{Cr}$ diffuses from the alloy bulk to the oxide scale-alloy interface. ${ }^{[202]}$ The kinetics of transition of $\mathrm{Fe} / \mathrm{Ni}$ oxide into protective layer of $\mathrm{Cr}_{2} \mathrm{O}_{3}$ depends on the supply of chromium by diffusion in the alloy matrix, which is governed profoundly by grain size of the alloy. As clearly demonstrated in the literature ${ }^{[203]}$ a relatively fine grain $(\sim 17 \mu \mathrm{m}$ or less $)$ $18 \mathrm{Cr}$ alloy easily developed a uniform layer of $\mathrm{Cr}_{2} \mathrm{O}_{3}$. For the same alloy with grain sizes greater than $40 \mu \mathrm{m}$, this protective layer of $\mathrm{Cr}_{2} \mathrm{O}_{3}$ was difficult to form during air-oxidation, as the inner layer of $(\mathrm{FeCr})_{3} \mathrm{O}_{4}$ continued to grow due to insufficient chromium supply. ${ }^{[204]}$ Low-chromium $\mathrm{Fe}-\mathrm{Cr}$ alloys fail to form a protective layer of $\mathrm{Cr}_{2} \mathrm{O}_{3} \cdot{ }^{[204-207]}$ The low-Cr alloys (15 to $60 \mu \mathrm{m}$ ) suffer predominant and extensive oxidation 

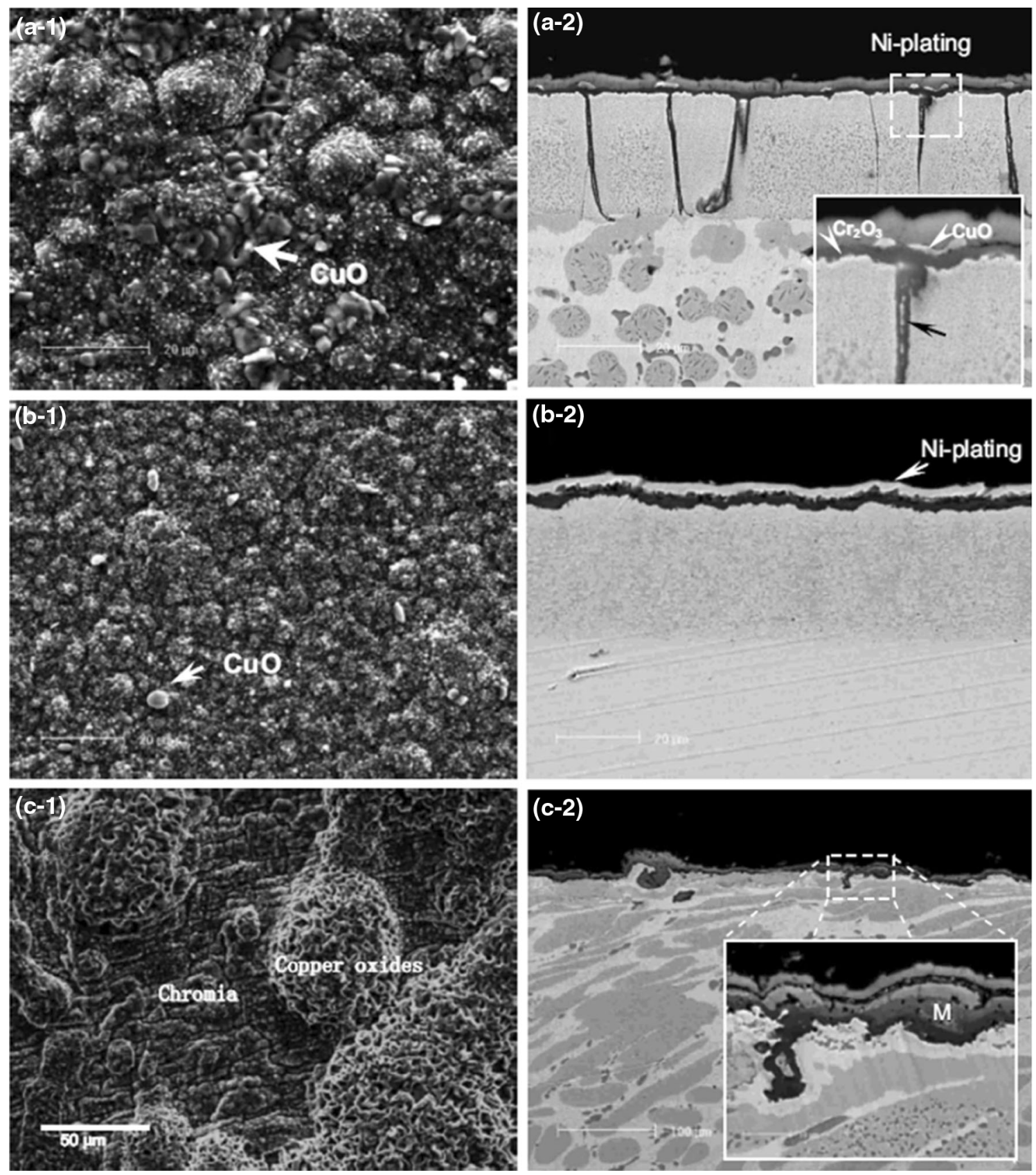

Fig. 18 - (a-1 through $c$-1) Surface and ( $a$-2 through $c$-2) cross-sectional SEM morphologies of the Cu-30Ni-20Cr nanocrystalline alloys in a form of DCMS $(a-1,2), \operatorname{NCE}(b-1,2)$, and $\operatorname{SMAT}(c-1,2)$ after $20 \mathrm{~h}$ oxidation in air at $1073 \mathrm{~K}\left(800{ }^{\circ} \mathrm{C}\right) \cdot{ }^{196]}$

along grain boundaries, and a decrease in grain size increases this internal oxidation. ${ }^{[206,207]}$

Singh Raman et al. ${ }^{[106]}$ have demonstrated a profound role of nanocrystalline (nc) structure in improving the oxidation resistance of $\mathrm{Fe}-\mathrm{Cr}$ binary alloys. Figure 19 shows a comparison between the oxidation kinetics of nanocrystalline vis-á-vis microcrystalline $\mathrm{Fe}-10 \mathrm{Cr}$ alloy in the temperature range $573 \mathrm{~K}$ to $673 \mathrm{~K}\left(300{ }^{\circ} \mathrm{C}\right.$ to $400{ }^{\circ} \mathrm{C}$ ). The striking features of the oxidation kinetics:

(a) After 3120 minutes of oxidation at $573 \mathrm{~K}\left(300{ }^{\circ} \mathrm{C}\right)$, weight gain of me was found to be nearly an order of magnitude greater than that of nc alloy of same composition. This influence is enhanced at $623 \mathrm{~K}$ and $673 \mathrm{~K}\left(350{ }^{\circ} \mathrm{C}\right.$ and $\left.400{ }^{\circ} \mathrm{C}\right)$.

(b) Both nc and $\mathrm{mc}$ alloys follow parabolic kinetics in the initial period (as was evidenced by the weightgain $^{2} v s$ time plots ${ }^{[106]}$ ). But, during subsequent oxidation, nc $\mathrm{Fe}-10 \mathrm{Cr}$ alloy showed a considerable departure from the parabolic behavior whereas mc alloy continued to follow parabolic kinetics.

(c) The considerable difference in the oxidation kinetics between $\mathrm{nc}$ and $\mathrm{mc}$ alloys after the initial period also manifests in some stark difference in color of the oxidized samples (insets in Figure 19). It is interest- 


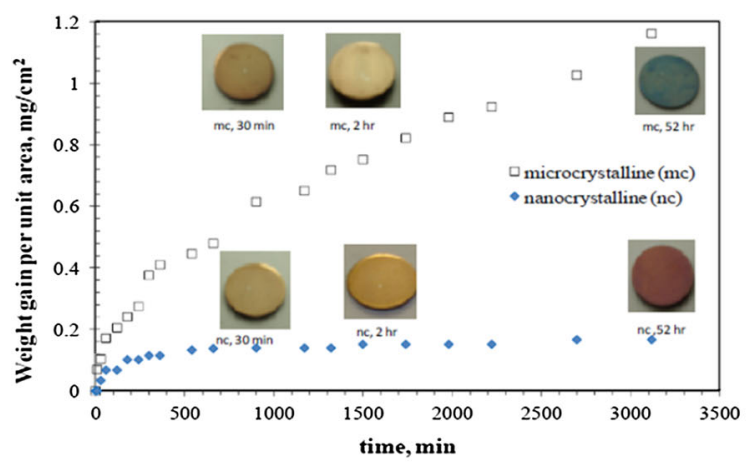

(a)

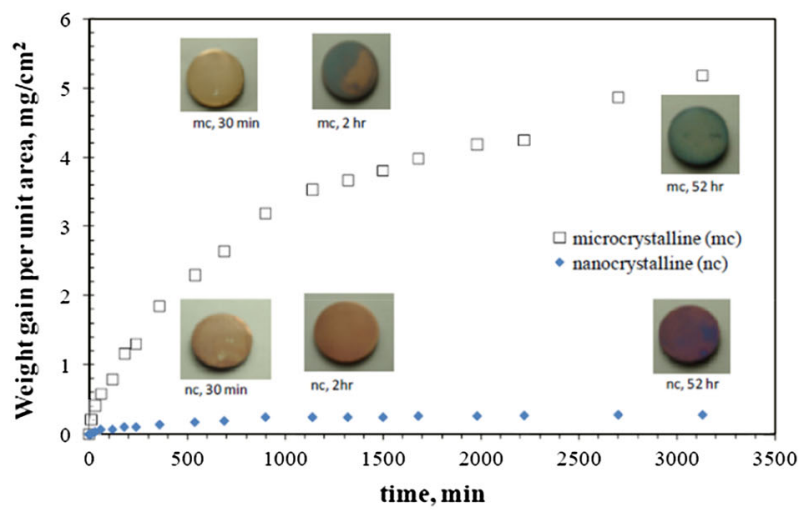

(b)

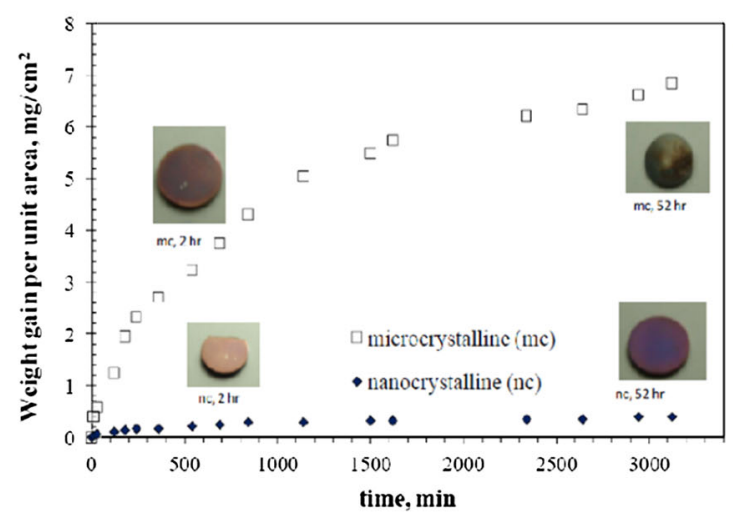

(c)

Fig. 19-Oxidation kinetics of nanocrystalline (nc) and microcrystalline (mc) $\mathrm{Fe}-10 \mathrm{Cr}$ alloys oxidized at (a) $573 \mathrm{~K}\left(300{ }^{\circ} \mathrm{C}\right)$, (b) $623 \mathrm{~K}$ $\left(350{ }^{\circ} \mathrm{C}\right)$, and (c) $673 \mathrm{~K}\left(400{ }^{\circ} \mathrm{C}\right.$ ) for $3120 \mathrm{~min}$ (insets showing color of the oxidized samples after different durations of oxidation). ${ }^{[8,106]}$

ing that the color of the nc alloy changed after the initial period in spite of no significant weight gain.

Oxidation kinetics of $\mathrm{nc}$ and $\mathrm{mc} \mathrm{Fe}-20 \mathrm{Cr}$ alloys at $623 \mathrm{~K}\left(350{ }^{\circ} \mathrm{C}\right)^{[106]}$ suggest only a little improvement in oxidation resistance due to nanocrystalline structure. However, what is most relevant is that the weight gain of the $\mathrm{mc} \mathrm{Fe}-20 \mathrm{Cr}$ alloy, at the end of 52-hours of oxidation, was similar to that of the nanocrystalline $\mathrm{Fe}-10 \mathrm{Cr}$ alloy, suggesting that the degree of oxidation resistance conferred due to nanocrystalline structure at only 10 pet chromium is similar to that of the alloy with

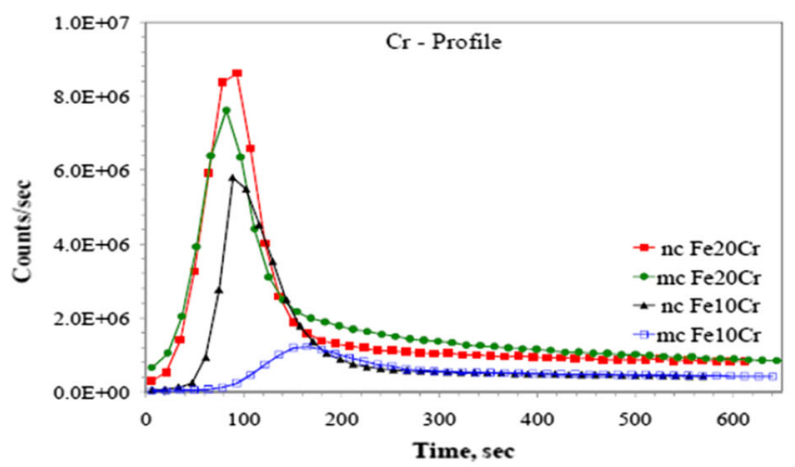

(a)

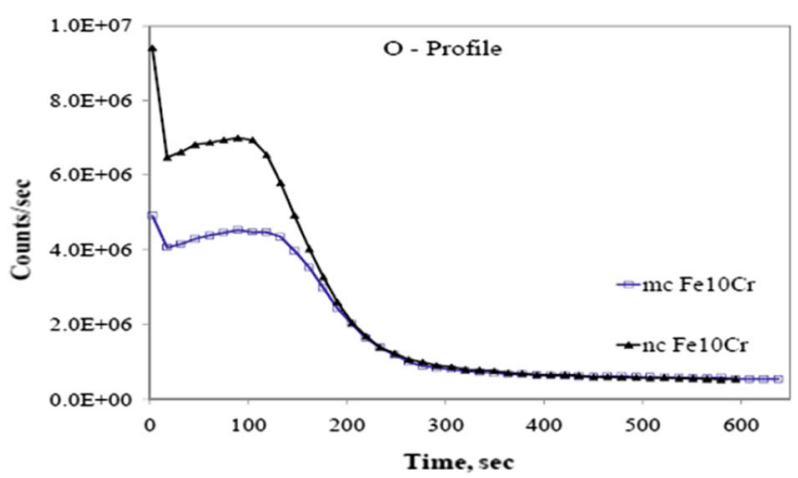

(b)

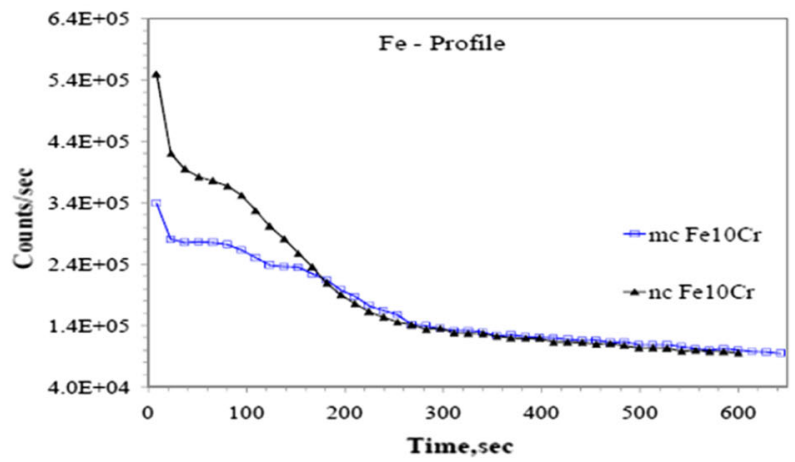

(c)

Fig. 20-SIMS depth profiles for $\mathrm{Cr}$, $\mathrm{O}$, and $\mathrm{Fe}$ in the oxide scales developed during oxidation at $573 \mathrm{~K}\left(300{ }^{\circ} \mathrm{C}\right)$ of nanocrystalline $(\mathrm{nc})$ and microcrystalline $(\mathrm{mc}) \mathrm{Fe}-10 \mathrm{pctCr}$ and $\mathrm{Fe}-20 \mathrm{Cr}$ alloys oxidized for 120 min. ${ }^{[8,106]}$

twice as much chromium but microcrystalline structure. Concentration profiles for $\mathrm{Cr}, \mathrm{Fe}$, and $\mathrm{O}$ along the depth of the oxide films (shown in Figures 20(a) through (c)) suggest the oxide film developed on $\mathrm{mc} F \mathrm{Fe}-10 \mathrm{Cr}$ alloy to be much thicker. The highest $\mathrm{Cr}$ content of the inner layer of nc $\mathrm{Fe}-10 \mathrm{Cr}$ alloy is considerably higher $(>4$ times) than the highest $\mathrm{Cr}$ content in the inner layer of mc Fe-10Cr alloy, as well as it is comparable to the chromium content of the inner oxide layer that develops on a $\mathrm{Fe}-20 \mathrm{Cr}$ microcrystalline alloy ${ }^{[106]}$ (which is well known to establish a protective layer of $\mathrm{Cr}_{2} \mathrm{O}_{3}$ ). Thus, the authors have concluded that the nanocrystalline $\mathrm{Fe}-10 \mathrm{Cr}$ alloys developed a protective oxide layer of 
$\mathrm{Cr}_{2} \mathrm{O}_{3}$, in spite of its considerably low chromium content. This was the first reported data suggesting the formation of $\mathrm{Cr}_{2} \mathrm{O}_{3}$ at 10 pct $\mathrm{Cr}$. It has been explained on the basis of the considerably higher $\mathrm{Cr}$ content of the inner oxide layer due to enhanced diffusion in a nanocrystalline matrix. In contrast, the inner oxide layer of the microcrystalline alloys with low-Cr $(<12 \mathrm{pct})$ would at best be a mixed spinel type $\mathrm{Fe}-\mathrm{Cr}$ mixed oxide. ${ }^{[204-207]}$ The authors have also reported a distinct difference in the color of the pellets of the nc and mc Fe$10 \mathrm{Cr}$ alloys, as a result of the difference in chemical composition (chromium content) and the thickness of the oxide scales developed over the two materials (Figure 19 (insets)). The nanocrystalline structure enhances the diffusion of beneficial alloying element (Al, $\mathrm{Cr}$ ) and thus accounts for the improved oxidation resistance. The rapid development of a protective oxide film in nanocrystalline alloys and the change in cation/ anion transport associated with such protective oxide films has been exploited in several $\mathrm{Cr}_{2} \mathrm{O}_{3}$ and $\mathrm{Al}_{2} \mathrm{O}_{3}$ forming alloys, as evidenced in several examples. In simplistic terms, one would expect this beneficial effect to be more profound with increasing temperature. However, there are several other considerations in the oxide growth of nanocrystalline alloys which has received limited attention, e.g., the role of nanocrystalline structure in adhesion of the oxide layer and spallation at high temperatures. In microcrystalline materials, adhesion has been studied extensively in terms of surface structure, chemistry, and electrostatics. ${ }^{[208]}$ The three main types of stresses driving spallation are ${ }^{[209,210]}$ :

1. Stress caused by the difference in thermal expansion coefficients of metal and oxide on cooling;

2. Interfacial stresses due to epitaxial strains: Epitaxial growth at the oxide-alloy interface is explained in terms of the adjustment of spacing of interface dislocations which usually result in tensile stress in the metal and compressive stress in the scale. Above a critical interfacial strain, the plastic deformation (by dislocation glide) in the metal and scale cannot be accommodated, leading to scale fracture and spallation.

3. Stresses developed isothermally due to oxide growth: The magnitude of stress depends on interface coherency, oxide microstructure, surface curvature and creep relaxation in the oxide.

Extensive modeling on the spallation and oxide growth in microcrystalline materials has established the mechanism of oxide-scale "buckling" and tensile crack propagation along the metal-oxide interface (Figure 21). ${ }^{[211,212]}$ However, in the case of nanocrystalline alloys, additional parameters can affect the interfacial stresses. The grain growth in nanocrystalline matrix at higher temperatures will affect the stresses at the oxide-alloy interface on three accounts: (a) scale plasticity and gradient in the oxide point-defect density will vary as the thickness of the oxide scale increases during the initial stages of oxidation, (b) dynamic grain growth in the matrix during oxidation will affect the incoherency at the oxide-alloy interface which is likely to affect the nucleation of interfacial cracks and decohesion of

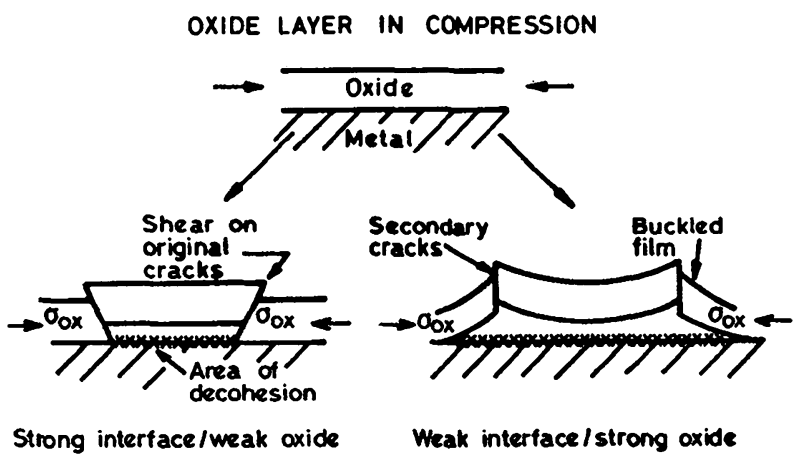

Fig. 21-Schematic representation of cracking, decohesion blistering and spallation in oxide scales under compression. ${ }^{[211,212]}$

oxide scale, and (c) Even after a uniform protective oxide film is formed, the increase in matrix grain size will affect the diffusion of protective alloying element which is required for the self-healing of the cracks developed in the oxide film after prolonged oxidation. Another aspect of oxidation in nanocrystalline substrates which is not understood is the effect of reactive element like $\mathrm{Zr}, \mathrm{Y}$, $\mathrm{Hf}, \mathrm{Ce}$, etc.

\section{SUMMARY}

1. As a result of their extremely fine grain size, nanocrystalline metals and alloys possess remarkably different properties. However, because such materials have poor thermal stability and are highly susceptible to grain growth, processing of artifact-free large scale bulk samples is a challenge.

2. The increase in the surface activity due to nanocrystalline structure significantly influences the electrochemical behavior of nanocrystalline metals/alloys.

3. There is currently no unified/conclusive theory on the effect of grain size reduction to nano-regime on the aqueous corrosion of metals and alloys. However, based on the experimental evidences, it can be concluded that during active dissolution and if the corrosion products are dissoluble, nanocrystallization increases the corrosion rate whereas if the corrosion products are insoluble, it decreases the rate of corrosion.

4. In the nanocrystalline alloys that have the ability to passivate, the pitting and localized corrosion is significantly reduced as compared to the microcrystalline alloys of same composition. Selective dissolution has been proposed as a convincing theory explaining this behavior. Recent studies have also shown that an empirical relationship between the corrosion current density and grain size can be established.

5. Alloys containing such elements that can form protective oxide scale (namely, $\mathrm{Cr}, \mathrm{Si}$, and $\mathrm{Al}$ ) have shown superior resistance to degradation due to high temperature oxidation. Nanocrystalline structure leads to the decrease in the critical amount of alloying element required for transition from internal to external oxidation. 
6. In case of Ni-based superalloys like K38G, KF17, and LDZ125, decreasing the grain size to nanocrystalline regime facilitates the formation of a continuous alumina oxide layer as opposed to their coarsegrained counterparts which form a mixture of $\mathrm{Ni}$, $\mathrm{Al}$, and $\mathrm{Cr}$ oxides.

7. In certain nanocrystalline alloys, the adhesion of oxide scale to the substrate has been found to be superior because of the micro-pegging effect. However, several other factors affecting the oxide-adhesion and spallation behavior are yet to be explored.

8. Recent studies have established that a nanocrystalline structure imparts superior oxidation resistance to an $\mathrm{Fe}-10 \mathrm{Cr}$ alloy (as compared to its microcrystalline counterpart) at moderately high temperatures [573 $\mathrm{K}$ to $673 \mathrm{~K}\left(300{ }^{\circ} \mathrm{C}\right.$ to $\left.\left.400{ }^{\circ} \mathrm{C}\right)\right]$. The oxidation resistance was similar to that of a microcrystalline Fe-20Cr alloy. This behavior is attributed to the much faster diffusion of chromium in the nanocrystalline (nc) alloy, and as a result, the ability of the nc alloy to develop a protective layer of chromium oxide (at much lower $\mathrm{Cr}$ contents as compared to the coarse-grained $\mathrm{Fe}-\mathrm{Cr}$ alloys).

\section{ACKNOWLEDGMENTS}

The motivation for accomplishing this review came from an experimental and theoretical work of recent years on corrosion/oxidation of nanocrystalline alloys in the authors' group. This program received funding support from Australian Research Council's Discovery Projects scheme, and has benefitted immensely from collaboration with Prof Carl Koch (North Carolina State University) for synthesis of the nanocrystalline alloys as well as from the dedicated work of the past graduate student, Dr. Rajeev Gupta.

\section{REFERENCES}

1. R.W. Siegel: Nanostruct. Mater., 1994, vol. 4 (1), pp. 121-38.

2. C. Suryanarayana and F. Froes: Metall. Trans. A, 1992, vol. 23A, pp. 1071-81.

3. H. Tanimoto, P. Farber, R. Würschum, R.Z. Valiev, and H.E. Schaefer: Nanostruct. Mater., 1999, vol. 12 (5-8), pp. 681-84.

4. C.C. Koch, K.M. Youssef, R.O. Scattergood, and K.L. Murty: Adv. Eng. Mater., 2005, vol. 7 (9), pp. 787-94.

5. K.D. Ralston and N. Birbilis: Corrosion, 2010, vol. 66(7), p. 075005 .

6. K.D. Ralston, N. Birbilis, and C.H.J. Davies: Scripta Mater., 2010, vol. 63 (12), pp. 1201-04

7. G.R. Argade, S.K. Panigrahi, and R.S. Mishra: Corros. Sci., 2012 , vol. 58, pp. $145-51$.

8. R.K.S. Raman and R.K. Gupta: Corros. Sci., 2009, vol. 51 (2), pp. 316-21.

9. R. Rofagha, U. Erb, D. Ostrander, G. Palumbo, and K.T. Aust: Nanostruct. Mater., 1993, vol. 2 (1), pp. 1-10.

10. R. Rofagha, R. Langer, A.M. El-Sherik, U. Erb, G. Palumbo, and K.T. Aust: Scripta Metall. Mater., 1991, vol. 25, p. 2867.

11. R. Kirchheim, X.Y. Huang, P. Cui, R. Birringer, and H. Gleiter: Nanostruct. Mater., 1992, vol. 1 (2), pp. 167-72.

12. H. Gleiter: Prog. Mater Sci., 1989, vol. 33 (4), pp. 223-315.

13. R.W. Siegel: Annu. Rev. Mater. Sci., 1991, vol. 21 (1), pp. 559-78.
14. R.W. Siegel: Nanostruct. Mater., 1993, vol. 3 (1-6), pp. 1-18.

15. G.J. Thomas, R.W. Siegel, and J.A. Eastman: Scripta Metall. Mater., 1990, vol. 24 (1), pp. 201-06.

16. R.W. Siegel: MRS Bull., 1990, vol. 15(10), p. 60

17. R.W. Siegel: Mater. Sci. Eng. A, 1993, vol. 168 (2), pp. $189-97$.

18. H.J. Fecht: Nanostruct. Mater., 1992, vol. 1 (2), pp. 125-30.

19. X. Zhu, R. Birringer, U. Herr, and H. Gleiter: Phys. Rev. B, 1987, vol. 35 , p. 9085

20. T. Haubold, R. Birringer, B. Lengeler, and H. Gleiter: Phys. Lett. A, 1989, vol. 135 (8-9), pp. 461-66.

21. T. Mütschele and R. Kirchheim: Scripta Metall., 1987, vol. 21 (8), pp. 1101-04.

22. J. Horvath, R. Birringer, and H. Gleiter: Solid State Commun., 1987, vol. 62 (5), pp. 319-22.

23. G. Wallner, E. Jorra, H. Franz, J. Peisl, R. Birringer, H. Gleiter, T. Haubold, and W. Petry: Mater. Res. Symp. Proc., 1989, vol. 132 , p. 49

24. H. Gleiter: Acta Mater., 2000, vol. 48 (1), pp. 1-29.

25. R. Birringer: Mater. Sci. Eng. A, 1989, vol. 117, pp. 33-43.

26. C. Suryanarayana: Int. Mater. Rev., 1995, vol. 40, pp. 41-64.

27. K. Lu: Mater. Sci. Eng. R, 1996, vol. 16, p. 61.

28. T.R. Malow and C.C. Koch: Acta Mater., 1997, vol. 45 (5), pp. $2177-86$.

29. J. Joardar, S.K. Pabi, H. Fecht, and B.S. Murthy: Philos. Mag. $A$, 2002, vol. 82, pp. 469-75.

30. E. Bonetti, L. Del Bianco, L. Pasquini, and E. Sampaolesi: Nanostruct. Mater., 1999, vol. 12 (5-8), pp. 685-88.

31. C.H. Moelle and H.J. Fecht: Nanostruct. Mater., 1995, vol. 6 (1-4), pp. 421-24.

32. R. Perez, H. Jiang, E. Lavernia, and C. Dogan: Metall. Mater. Trans. A, 1998, vol. 29A, pp. 2469-75.

33. H. Natter, M. Schmelzer, M.S. Loffler, C.E. Krill, A. Fitch, and R. Hempelmann: J. Phys. Chem. B, 2000, vol. 104 (11), pp. 246776.

34. H. Natter, M. Schmelzer, M.S. Loffler, and R. Hempelmann: Mater. Sci. Forum, 2000, vols. 343-346, p. 726.

35. R.J. Perez, H.G. Jiang, and E.J. Lavernia: Nanostruct. Mater., 1997, vol. 9 (1-8), pp. 71-74.

36. X. Song, J. Zhang, L. Li, K. Yang, and G. Liu: Acta Mater., 2006, vol. 54 (20), pp. 5541-50.

37. K. Omura, H. Miura, and H. Ogawa: Mater. Sci. Forum, 1999 , vols. $318-320$, p. 479.

38. J. Weissmuller: Nanostruct. Mater., 1993, vol. 3, pp. 261-72.

39. P. Wynblatt and R.C. Ku: Surf. Sci., 1977, vol. 65, pp. 511-31.

40. P.C. Millett, R.P. Selvam, and A. Saxena: Acta Mater., 2006, vol. 54 , pp. 297-303

41. C.E. Krill, R. Klen, S. Janes, and R. Birringer: Mater. Sci. Forum, 1995, vols. 179-181, p. 443.

42. K.A. Darling, R.N. Chan, P.Z. Wong, J.E. Semones, R.O. Scattergood, and C.C. Koch: Scripta Mater., 2008, vol. 59 (5), pp. 530-33.

43. A. Michels, C.E. Krill, H. Ehrhardt, R. Birringer, and D.T. Wu: Acta Mater., 1999, vol. 47 (7), pp. 2143-52.

44. X. Zhang, N.Q. Vo, P. Bellon, and R.S. Averback: Acta Mater., 2011, vol. 59, pp. 5332-41.

45. N.Q. Vo, S.W. Chee, D. Schwen, X. Zhang, P. Bellon, and R.S. Averback: Scripta Mater., 2010, vol. 63, pp. 425-32.

46. T. Frolov, K.A. Darling, L.J. Kecskes, and Y. Mishin: Acta Mater., 2012, vol. 60 (5), pp. 2158-68.

47. S. Trapp, C.T. Limbach, U. Gonser, S.J. Campbell, and H. Gleiter: Phys. Rev. Lett., 1995, vol. 75(20), p. 3760.

48. A. Hernando, A. Cebollada, J.L. Menendez, and F. Briones: Electronic Transport in Nanocrystalline Iron: A Low T Magnetoresistance Effect, Elsevier, San Diego, CA, 2003, vol. 262, p. 1.

49. G.E. Fougere, J.R. Weertman, and R.W. Siegel: Nanostruct. Mater., 1995, vol. 5 (2), pp. 127-34.

50. D. Segers, S. Van Petegem, J.F. Löffler, H. Van Swygenhoven, W. Wagner, and C. Dauwe: Nanostruct. Mater., 1999, vol. 12 (5-8), pp. 1059-62.

51. A.A. Karimpoor, U. Erb, K.T. Aust, and G. Palumbo: Scripta Mater., 2003, vol. 49 (7), pp. 651-56.

52. T.R. Malow and C.C. Koch: Acta Mater., 1998, vol. 46 (18), pp. 6459-73.

53. T. Malow and C. Koch: Metall. Mater. Trans. A, 1998, vol. 29A, pp. 2285-95. 
54. A.S. Khan, H. Zhang, and L. Takacs: Int. J. Plast., 2000, vol. 16 (12), pp. 1459-76.

55. B. Chen, D. Penwell, M.B. Kruger, A.F. Yue, and B. Fultz: $J$. Appl. Phys., 2001, vol. 89(9), p. 4794.

56. H. Fecht, E. Hellstern, Z. Fu, and W. Johnson: Metall. Trans. A, 1990, vol. 21, pp. 2333-37.

57. L. Daróczi, D.L. Beke, G. Posgay, G.F. Zhou, and H. Bakker: Nanostruct. Mater., 1993, vol. 2 (5), pp. 515-25.

58. P. Sinha and G.S. Collins: Hyperfine Interact., 1994, vol. 92(1), pp. 949-53.

59. E. Bonetti, L. Del Bianco, D. Fiorani, D. Rinaldi, R. Caciuffo, and A. Hernando: Phys. Rev. Lett., 1999, vol. 83(14), p. 2829.

60. E. Bonetti, G. Scipione, G. Valdrè, S. Enzo, R. Frattini, and P.P. Macrì: J. Mater. Sci., 1995, vol. 30 (9), pp. 2220-26.

61. T.R. Malow, C.C. Koch, P.Q. Miraglia, and K.L. Murty: Mater. Sci. Eng. A, 1998, vol. 252 (1), pp. 36-43.

62. S. Szabó, D.L. Beke, L. Harasztosi, L. Daróczi, G. Posgay, and M. Kis-Varga: Nanostruct. Mater., 1997, vol. 9 (1-8), pp. 527-30.

63. O. Elkedim, H.S. Cao, C. Meunier, and E. Gaffet: Mater. Sci. Forum, 1998, vols. 269-272, pp. 843-48.

64. O. Elkedim, H.S. Cao, and P. Fluzin: Mater. Sci. Forum, 1999, vols. $312-314$, p. 635.

65. H.H. Tian and M. Atzmon: Acta Mater., 1999, vol. 47 (4), pp. $1255-61$.

66. E. Sobczak, Y. Swilem, N.N. Dorozhkin, R. Nietubyc, P. Dluzewski, and A. Slawska-Waniewska: J. Alloy. Compd., 2001, vol. 328 (1-2), pp. 57-63.

67. S. Cheng, E. Ma, Y.M. Wang, L.J. Kecskes, K.M. Youssef, C.C. Koch, U.P. Trociewitz, and K. Han: Acta Mater., 2005, vol. 53 (5), pp. 1521-33.

68. C.C. Koch: Rev. Adv. Mater. Sci., 2003, vol. 5 (2), p. 91.

69. G.D. Hibbard, K.T. Aust, and U. Erb: Mater. Sci. Eng. A, 2006, vol. 433 (1-2), pp. 195-202.

70. J.H. Seo, J.K. Kim, T.H. Tim, and Y.B. Park: Mater. Sci. Forum, 2005, vols. 475-479, p. 457.

71. K.M. Youssef, R.O. Scattergood, K.L. Murty, J.A. Horton, and C.C. Koch: Appl. Phys. Lett., 2005, vol. 87 (9), pp. 1-3.

72. K.M. Youssef, R.O. Scattergood, K.L. Murty, and C.C. Koch: Scripta Mater., 2006, vol. 54 (2), pp. 251-56.

73. J.R. Groza: in Nanostructured Materials: Processing, Properties, and Applications, C.C. Koch, ed., William Andrew Publication, Norwich, NY, 2007.

74. K.M. Youssef, R.O. Scattergood, K.L. Murty, and C.C. Koch: Appl. Phys. Lett., 2004, vol. 85 (6), pp. 929-31.

75. O. Elkedim, H.S. Cao, and D. Guay: J. Mater. Process. Technol., 2002, vol. 121 (2-3), pp. 383-89.

76. A.P. Zhilyaev, S. Lee, G.V. Nurislamova, R.Z. Valiev, and T.G. Langdon: Scripta Mater., 2001, vol. 44, pp. 2753-58.

77. A.P. Zhilyaev, G.V. Nurislamova, B.K. Kim, M.D. Baro, J.A. Szpunar, and T.G. Langdon: Acta Mater., 2003, vol. 51, pp. 753-65.

78. M. Furukawa, Z. Horita, M. Nemoto, and T.G. Langdon: $J$. Mater. Sci., 2001, vol. 36, pp. 2835-43.

79. Y. Iwahashi, Z. Horita, M. Nemoto, and T.G. Langdon: Acta Mater., 1998, vol. 46, pp. 3317-31.

80. Y. Iwahashi, J.T. Wang, Z. Horita, M. Nemoto, and T.G. Langdon: Scripta Mater., 1996, vol. 35, pp. 143-46.

81. T.G. Langdon, M. Furukawa, M. Nemoto, Z. Horita, and J. Miner: Met. Mater. Soc., 2000, vol. 52, pp. 30-33.

82. M. Nemoto, Z. Horita, M. Furukawa, and T.G. Langdon: Met. Mater. Int., 1998, vol. 4, pp. 1181-90.

83. R.W. Siegel: Mater. Sci. Forum, 1997, vols. 235-238, pp. 851-60.

84. R. Gupta, R.K.S. Raman, and C.C. Koch: Mater. Sci. Eng. A, 2008, vol. 494 (1-2), pp. 253-56.

85. M. Jain and T. Christman: Acta Metall. Mater., 1994, vol. 42 (6), pp. 1901-11.

86. L. Fu, J. Yang, Q. Bi, and W. Liu: Nanoscale Res. Lett., 2008, vol. 4, pp. 11-16.

87. G.-G. Lee and S.-D. Kim: Mater. Res. Symp. Proc., 2003, vol. 740 , p. I3.22.

88. K. Tanaka, T. Fukuzaki, K. Nishio, and R. Tamura: Journal of Physics: 3rd International Symposium of Atomic Technology, 2009, vol. 191, p. 012025.

89. M. Yue, P.L. Niu, J.X. Zhang, and D.T. Zhang: IEEE Trans. Magn., 2006, vol. 42(10), p. 2894.
90. T. Saito, T. Takeuchi, and H. Kageyama: J. Mater. Res., 2004, vol. 19(9), p. 2730.

91. B.S. Murthy, M.K. Datta, and S.K. Pabi: Sadhana, 2003, vol. 28 (1-2), pp. 23-45.

92. G.C. Hadjipanayis and R.W. Siegel: Nanophase Materials: Synthesis, Properties, Applications, Kluwer Academic, Dordrecht, 1994.

93. J. Loffler and J. Weissmuller: Phys. Rev. B, 1995, vol. 52(10), p. 7076.

94. H.N. Fraze, B. Fultz, J.L. Roberts, and S. Spooner: Philos. Mag., 2000, vol. B80, p. 1545.

95. H.V. Swygenhoven, D. Farkas, and A. Caro: Phys. Rev. Lett., 2000, vol. B62, p. 831.

96. L. Del Bianco, A. Hernando, E. Bonetti, and E. Navarro: Phys. Rev. Lett., 1997, vol. 81, p. 4500

97. J. Balogh, L. Bujdoso, D. Kaptas, T. Kemeny, I. Vincze, S. Szabó, and D.L. Beke: Phys. Rev., 2000, vol. B61, p. 4109.

98. K. Lu and Y.H. Zhao: Nanostruct. Mater., 1999, vol. 12, p. 559.

99. R.B. Intrui and Z. Szklarska-Smialowska: Corrosion, 1992, vol. 48 , p. 398.

100. S. Shriram, S. Mohan, N.G. Renganathan, and R. Venkatachalam: Trans. IMF, 2000, vol. 78(5), p. 194.

101. Z. Liu, T. Wu, K. Dahm, and F. Wang: Scripta Mater., 2002, vol. 37, p. 1151

102. X.Y. Wang and D.Y. Li: Electrochim. Acta, 2002, vol. 47 (24), pp. 3939-47.

103. R.V.S. Rao, U. Wolff, S. Baunack, J. Eckert, and A. Gebert: $J$. Mater. Res., 2003, vol. 18, p. 97.

104. A. Gebert, U. Wolf, A. John, J. Eckert, and L. Schultz: Mater. Sci. Eng. A, 2001, vol. 299, p. 125.

105. M. Nakamura, N. Ikemiya, A. Iwasaki, Y. Suzuki, and M. Ito: $J$. Electroanal. Chem., 2004, vol. 566, p. 385.

106. R.K.S. Raman, R.K. Gupta, and C.C. Koch: Philos. Mag. A, 2010, vol. 90 (23), pp. 3233-60.

107. H. Jung and A. Alfantazi: Electrochim. Acta, 2006, vol. 51 (8-9), pp. $1806-14$.

108. G. Palumbo, F. Gonzalez, A.M. Brennenstuhl, U. Erb, W. Shmayda, and P.C. Lichtenberger: Nanostruct. Mater., 1997, vol. $9(1-8)$, pp. 737-46.

109. L.B. Wang, Y. Lin, Z. Zeng, W. Liu, Q. Xue, L. Hu, and J.X. Zhang: Electrochim. Acta, 2007, vol. 52, p. 4342.

110. A. Vinogradov, T. Mimaki, S. Hashimoto, and R.Z. Valiev: Mater. Sci. Forum, 1999, vols. 312-314, p. 593.

111. S.J. Thorpe, B. Ramaswami, and K.T. Aust: J. Electrochem. Soc., 1988, vol. 135, pp. 2162-70.

112. D. Cheng, V.L. Tellkamp, C.J. Lavernia, and E.J. Lavernia: Ann. Biomed. Eng., 2001, vol. 29 (9), pp. 803-09.

113. L. Lu, L.B. Wang, B.Z. Ding, and K. Lu: Mater. Sci. Eng. A, 2000, vol. 286 (1), pp. 125-29.

114. S. Wang, R. Rofagha, P.R. Roberge, and U. Erb: Electrochem. Soc. Proc., 1995, vols. 95-98, p. 244.

115. P.T. Tang, T. Watanabet, J.E.T. Andersen, and G. Bech-Nielsen: J. Appl. Electrochem., 1995, vol. 25 (4), pp. 347-52.

116. L. Liu, Y. Li, and F. Wang: Electrochim. Acta, 2007, vol. 52 (25), pp. 2392-2400.

117. S.H. Kim, K.T. Aust, U. Erb, F. Gonzalez, and G. Palumbo: Scripta Mater., 2003, vol. 48 (9), pp. 1379-84.

118. S.K. Ghosh, G.K. Dey, R.O. Dusane, and A.K. Grover: J. Alloy. Compd., 2006, vol. 426 (1-2), pp. 235-43.

119. F. Gonzalez, A.M. Brennenstuhl, G. Palumbo, U. Erb, and P.C. Lichtenberger: Mater. Sci. Forum, 1996, vols. 225-227, pp. 83136.

120. M. Yamashita, T. Mimaki, S. Hashimoto, and S. Miura: Philos. Mag. A, 1991, vol. 63 (4), pp. 707-26.

121. A. Aledresse and A. Alfantazi: J. Mater. Sci., 2004, vol. 39 (4), pp. $1523-26$.

122. A. Barbucci, G. Farne, P. Matteazzi, R. Riccieri, and G. Cerisola: Corros. Sci., 1998, vol. 41 (3), pp. 463-75.

123. L. Liu, Y. Li, and F. Wang: J. Mater. Sci. Technol., 2010, vol. 26 (1), pp. $1-14$.

124. R. Gupta, R.K.S. Raman, and C. Koch: J. Mater. Sci., 2012, vol. 47 (16), pp. 6118-24.

125. M. Yeganeh and M. Saremi: Surf. Coat. Technol., 2010, vol. 205, pp. 2218-24. 
126. S.H. Kim, K.T. Aust, U. Erb, and F. Gonzalez: Proc. American Electroplaters and Surface Finishers Society (AESF) SUR/FIN (2002), Orlando, FL.

127. Y. Li, F. Wang, and G. Liu: J. Chin. Soc. Corros. Proc., 2001, vol. 21, p. 215.

128. E.E. Oguzie, Y. Li, and F. Wang: Electrochim. Acta, 2007, vol. 52 , p. 6988.

129. R.K. Gupta, R.K.S. Raman, C.C. Koch, and B.S. Murthy: Int. J. Electrochem. Sci., 2013, vol. 8, pp. 6971-6806.

130. G. Meng, Y. Li, and F. Wang: Electrochim. Acta, 2006, vol. 51 (20), pp. 4277-84

131. H.Y. Tong, F.G. Shi, and E.J. Lavernia: Scripta Metall. Mater., 1995, vol. 32 (4), pp. 511-16.

132. C.T. Kwok, F.T. Cheng, H.C. Man, and W.H. Ding: Mater. Lett., 2006, vol. 60 (19), pp. 2419-22.

133. W. Ye, Y. Li, and F. Wang: Electrochim. Acta, 2006, vol. 51 (21), pp. 4426-32.

134. G. Ji, O. Elkedim, and T. Grosdidier: Surf. Coat. Technol., 2005, vol. 190, pp. 406-16.

135. W. Zeiger, M. Schneider, D. Scharnweber, and H. Worch: Nanostruct. Mater., 1995, vol. 6, pp. 1013-16.

136. G. Gupta, A.P. Moon, and K. Mondal: Bull. Mater. Sci., 2013 , vol. 36, pp. 51-58.

137. A.A. El-Moneim, A. Gebert, F. Schneider, O. Gutfleisch, and L. Schultz: Corr. Sci., 2002, vol. 44, pp. 1097-12.

138. A.A. El-Moneim, A. Gebert, M. Uhlemann, O. Gutfleisch, and L. Schultz: Corr. Sci., 2002, vol. 44, pp. 1857-74.

139. A.A. El-Moneim, O. Gutfleisch, A. Plotnikov, and A. Gebert: $J$. Magn. Magn. Mater., 2002, vol. 248, pp. 121-33.

140. H.B. Lu, Y. Li, and F. Wang: Thin Solid Films, 2006, vol. 510, p. 197.

141. H.B. Lu, Y. Li, and F. Wang: Surf. Coat. Technol., 2006, vol. 201, p. 3393.

142. A. Nikfahm, I. Danaee, A. Ashrafi, and M. Toroghinejad: Mater. Res., 2013, vol. 16 (6), pp. 1379-86.

143. K.M. Youssef, C. Koch, and P.S. Fedkiw: Corros. Sci., 2004, vol. 46, p. 51

144. J. Bhattarai, E. Akiyama, H. Habazzal, A. Kawashima, K. Asamai, and K. Hashimoto: Corros. Sci., 1998, vol. 40, pp. $757-$ 79 .

145. D. Zander and U. Koster: Mater. Sci. Eng. A, 2004 , vols. 375-377, pp. 53-59.

146. R. Rofagha, R. Langer, A.M. El-Sherik, U. Erb, G. Palumbo, and K.T. Aust: Mater. Res. Soc. Symp. Proc., 1992, vol. 238, p. 751 .

147. V. Afshari: Anti-Corrosion Methods Mater., 2010, vol. 57 (3), pp. $142-47$.

148. G. Song, B. Johannesson, S. Hapugoda, and D. StJohn: Corros. Sci., 2004, vol. 46 (4), pp. 955-77.

149. S.H. Kim, U. Erb, K.T. Aust, F. Gonzalez, and G. Palumbo: Plat. Surf. Finish., 2004, vol. 91(4), p. 68.

150. L. Liu, Y. Li, and F. Wang: Electrochim. Acta, 2008, vol. 54, pp. $768-80$.

151. Y. Li, T. Zhang, and F. Wang: Electrochim. Acta, 2006, vol. 51, pp. 2845-50.

152. G. Meng: Ph.D. Thesis, Institute of Metals Research, Chinese Academy of Sciences, 2005.

153. W. Ye, Y. Li, and F. Wang: Electrochim. Acta, 2009, vol. 54, pp. 1339-49.

154. B. Zhang, Y. Li, and F. Wang: Corros. Sci., 2007, vol. 47, pp. 2071-82.

155. M. Eskandari, M. Yeganeh, and M. Motamedi: Micro Nano Lett., 2012, vol. 7 (4), pp. 380-83.

156. A.Q. Lu, Y. Zhang, Y. Li, G. Liu, H.Q. Zang, and C.M. Liu: Acta Metall. Sin., 2006, vol. 19, p. 183.

157. R. Kirchheim, B. Heine, H. Fischmeister, S. Hofmann, H. Knote, and U. Stolz: Corros. Sci., 1989, vol. 29, p. 899.

158. H. Fischmeister, U. Roll, and Z. Anal: Chemistry, 1984, vol. 319, p. 639

159. P. Brusech, K. Muller, A. Atrens, and H. Neff: Appl. Phys., 1985, vol. 38A, p. 1.

160. T.N. Vu, P. Volovitch, and K. Ogle: Corros. Sci., 2013, vol. 67, pp. 42-49.

161. V.I. Pokhmurs'kyi, M.S. Khoma, V.I. Kopylets', and S.A. Kornii: Mater. Sci., 2003, vol. 39, p. 394.
162. H. Jung and A. Alfantazi: Corrosion, 2007, vol. 63 (2), pp. 159 170 .

163. L. Mihailov, M. Redzheb, and T. Spassov: Corros. Sci., 2013, vol. 74, pp. 308-13.

164. N. Birbilis, K.D. Ralston, S. Virtanen, H.L. Fraser, and C.H.J. Davies: Corros. Eng. Sci. Technol., 2010, vol. 45, pp. 224-30.

165. C. Op't Hoog, N. Birbilis, M.X. Zhang, and Y. Estrin: Key Eng. Mater., 2008, vol. 384, p. 229.

166. P. Kofstad: High Temperature Corrosion, Elsevier Applied Science and Publishers Ltd., New York, 1988.

167. C. Wagner: J. Electrochem. Soc., 1952, vol. 369, p. 103.

168. O. El Kedim, S. Paris, C. Phigini, F. Bernard, E. Gaffet, and Z.A. Munir: Mater. Sci. Eng. A, 2004, vol. 369 (1-2), pp. 49-55.

169. D.H. Boone and P. Deb: J. Vac. Sci. Technol., 1985, vol. A3, p. 2557.

170. P. Deb and D.H. Boone: J. Vac. Sci. Technol., 1985, vol. A3, p. 2578.

171. M. Dust, P. Deb, and D.H. Boone: J. Vac. Sci. Technol., 1986, vol. A4, p. 2571

172. M.R. Jackson and J.R. Rairdden: Metall. Trans., 1977, vol. 8A, p. 1697.

173. E. Godlewska and K. Godlewski: Oxid. Met., 1984, vol. 22(3-4), pp. 117-131.

174. J.R. Nicholls and D.J. Stephenson: Surf. Eng., 1991, vol. 7, p. 156.

175. D.H. Boone: Mater. Sci. Technol, 1986, vol. 2, p. 220.

176. T.A. Talor et al.: J. Vac. Sci. Technol., 1985, vol. A3, p. 2526.

177. D.S. Richeby and M.I. Wood: J. Vac. Sci. Technol., 1986, vol. A4, p. 2557.

178. S. Stecura: NASA TMX-3425, 1976

179. S. Stecura and H. Curt: US Patent 4, 705, 1977.

180. C.H. Liebert: Thin Solid Films, 1978, vol. 64, p. 329.

181. F. Wang and S. Geng: Surf. Eng., 2003, vol. 19(1), p. 32.

182. H. Lou, F. Wang, B. Xia, and L. Zhang: Oxid. Met., 1992, vol. 38 , p. 299.

183. H. Lou, F. Wang, S. Zhu, B. Xia, and L. Zhang: Surf. Coat. Technol., 1994, vol. 63, p. 105.

184. H. Lou, Y. Tang, X. Sun, and H. Guan: Mater. Sci. Eng. A, 1996, vol. 207 , p. 121

185. J. Zhang and H. Lou: Corros. Sci. Prot. Technol., 1998, vol. 10, p. 82 .

186. J.X. Zhang and H. Lou: Acta Metall. Sin., 1998, vol. 34, p. 627.

187. F. Wang: Ph.D. Thesis, Institute of Corrosion and Protection of Metals, The Chinese Academy of Sciences, 1992.

188. Z. Liu, W. Gao, K. Dahm, and F. Wang: Scripta Mater., 1997, vol. 37 , p. 1551

189. Z. Liu, W. Gao, K. Dahm, and F. Wang: Acta Mater., 1998, vol. 46, p. 1691

190. F.H. Stott, G.C. Wood, and J. Stringer: Oxid. Met., 1995, vol. 44, p. 113.

191. G.F. Chen and H. Lou: Mater. Lett., 2000, vol. 45, pp. 286-91.

192. G. Chen and H. Lou: Oxid. Met., 2000, vol. 54 (1), pp. 155-162.

193. G.F. Chen and H. Lou: Oxid. Met., 2000, vol. 53(5/6), p. 467.

194. Y.J. Xi and Y.J. Liu: Bull. Mater. Sci., 2011, vol. 34 (4), pp. 81114.

195. F. Wang: Oxid. Met., 1997, vol. 48 (3), pp. 215-24.

196. Y. Zhang, X. Peng, and F. Wang: Mater. Lett., 2004, vol. 58, pp. 1134-38.

197. J.X. Song, W.T. Wu, Y. Niu, and C.L. Wang: High Temp. Mater. Process., 1999, vol. 19 (2), pp. 117-25.

198. Y. Niu, J.X. Song, F. Gesmundo, and G. Farne: Oxid. Met., 2000, vol. 55 (3/4), pp. 291-305.

199. Z. Huang, X. Peng, C. Xu, and F. Wang: J. Electron Soc., 2009, vol. 156(3), pp. C95-C102.

200. D. Sebayang, D.S. Khaerudini, H. Saryanto, M.A. Othman, T. Sujitno, and P. Untoro: Key Eng. Mater., 2011, vols. 474-476, pp. 2134-39

201. Z.B. Wang, N.R. Tao, W.P. Tong, J. Lu, and K. Lu: Acta Mater., 2003, vol. 51, pp. 4319-29.

202. S. Leistikow, I. Wolf, and H.J. Grabke: Werkst. Korros., 1987, vol. 38 , p. 556

203. Y. Shida, N. Ohtsuka, J. Muriama, N. Fujino, and H. Fujikawa: Proc. JIMS-3, High Temp. Corros. Trans. Jap. Inst. Met., 1983.

204. R.K.S. Raman: Metall. Mater. Trans. A, 1995, vol. 26A, pp. 1847-58. 
205. R.K.S. Raman: Metall. Mater. Trans. A, 1998, vol. 29A, pp. 577 86.

206. R.K.S. Raman, J.B. Gnanamoorthy, and S.K. Roy: Trans. Indian Inst. Met., 1992, vol. 46, p. 391.

207. R.K.S. Raman, A.S. Khanna, and J.B. Gnanamoorthy: J. Mater. Sci. Lett., 1990, vol. 9, p. 353.

208. A.M. Stoneham and P.W. Tasker: Ceramic Microstructures 86: Role of Interfaces, Plenum, New York, 1988.
209. J. Stringer: Werkst. Korros., 1972, vol. 23, p. 747.

210. J. Stringer and G.C. Wood: Mater. Res. Soc. Symp. Proc., 1988, vol. 119 , p. 185.

211. H.E. Evans: Mater. Sci. Technol., 1988, vol. 4, p. 415.

212. H.E. Evans, G.P. Mitchell, R.C. Lobb, and D.R. Owen: Tech. Rep. Nuclear Electric Report, Technology Division TD/FCB/ $\mathrm{REP} / 0070$.

213. I. Kim: Met. Mater. Int., 2001, vol. 7 (5), pp. 471-77. 